\title{
ANNEXE 1 : EXAMEN DES DONNÉES PROBANTES SUR L'EXPOSITION PROFESSIONNELLE DES OUVRIERS DES PORCHERIES ET DES POULAILLERS
}

Remarque : La prescription de recommandations concernant la vaccination des ouvriers des porcheries à des fins de protection des troupeaux de porcs ne fait pas partie de la mission du CCNI. Pour ce qui est de préoccupations concernant la santé animale, le lecteur aura intérêt à consulter les ressources pertinentes.

\section{Préambule}

Le Comité consultatif national de l'immunisation (CCNI) donne à l'Agence de la santé publique du Canada (ASPC) (ci-après appelée l'Agence) des conseils continus et à jour liés à l'immunisation dans le domaine de la médecine, des sciences et de la santé publique. L'Agence reconnaît que les conseils et les recommandations figurant dans cette déclaration reposent sur les meilleures connaissances scientifiques actuellement accessibles et diffuse le présent document aux fins d'information. Les personnes qui administrent le(s) vaccin(s) doivent également connaître le contenu de la ou des monographies pertinentes sur le produit. Les recommandations d'utilisation du CCNI et les autres renseignements qui figurent ici peuvent différer du contenu des monographies de produit. Les fabricants ont fait approuver les vaccins et ont démontré leur innocuité et leur efficacité uniquement lorsqu'ils sont utilisés conformément à la monographie du produit. Les membres du CCNI et les agents de liaison doivent se conformer à la politique de I'ASPC régissant les conflits d'intérêts, et notamment déclarer chaque année les conflits d'intérêts possibles.

Membres du CCNI : Dre B. Warshawsky (présidente), Dre N. Crowcroft, DrI. Gemmill, Dre B. Henry, Dre D. Kumar, Dre S. McNeil, Dre C. Quach-Thanh, Dre M. Salvadori, Dr B. Seifert, Dre N. Sicard, Dre W. Vaudry, Dr R. Warrington.

Représentants chargés de la liaison : D ${ }^{r e} S$. Deeks (Association canadienne de santé publique), $D^{r e} A$. Mawle (Centres for Disease Control and Prevention, États-Unis), Dre D. Moore (Société canadienne de pédiatrie), Dre H. Morrison (Conseil des médecins hygiénistes en chef), Dre A. Opavsky (Association pour la microbiologie médicale et I'infectiologie Canada), Dre A. Pham-Huy (Association canadienne pour la recherche et l'évaluation en immunisation), Dre S. Rechner (Collège des médecins de famille du Canada), Dre V. Senikas (Société des obstétriciens et gynécologues du Canada).

Représentants d'office : Dre M. Carew (Direction générale de la santé des Premières nations et des Inuits, Santé Canada), Dr (Lcol) P. Egan (ministère de la Défense nationale), Dre A. Klein (Direction des produits biologiques et des thérapies génétiques, Santé Canada), Dre B. Law (Centre de l'immunisation et des maladies respiratoires infectieuses, ASPC), Dre C. Légaré (Bureau des produits biologiques, biotechnologiques et de santé naturels commercialisés, Santé Canada), Dre B. Raymond (Centre de l'immunisation et des maladies respiratoires infectieuses, ASPC/Comité canadien d'immunisation), M'me M. St-Laurent (Division de la surveillance et de l'intervention en cas d'épidémie, ASPC).

Le CCNI tient à remercier la contribution des : Dr O. Baclic, Dre B. Cholin, Dre S. Desai, Dr S. Halperin, Dre P. Huston, Dre J. Langley, Dre A. McGeer et Dr P. Van Buynder.

Spécialistes de la santé animale : Dre J. Keenliside (Alberta Agriculture and Rural Development), D' J. Dhanda (Agence canadienne d'inspection des aliments), Dr J. Copps (Centre national des maladies animales exotiques), Dr A. Harchaoui (Agence canadienne d'inspection des aliments), Dr B. Radke (British Columbia Centre for Disease Control) et Dr R. Arora (Agence canadienne d'inspection des aliments). 


\section{Table des matières}

Préambule

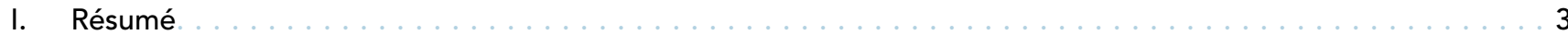

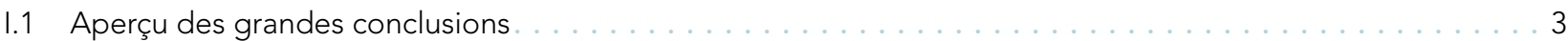

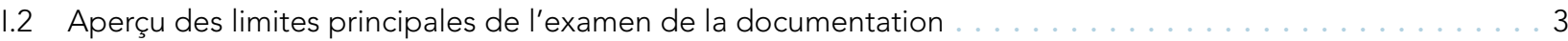

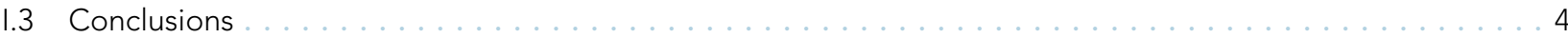

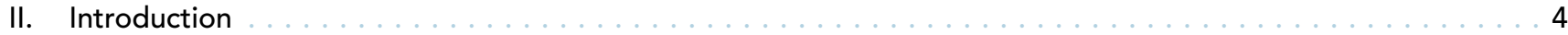

II.1 Épidémiologie des virus de la grippe d'origine animale . . . . . . . . . . . . . . . .

II.2 Risque pandémique . . . . . . . . . . . . . . . . . . . . . . . .

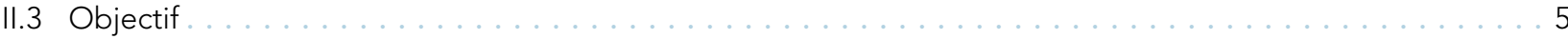

III. Méthodologie . . . . . . . . . . . . . . . . . . . . . . .

III.1 Rapport d'intervention rapide de l'Agence canadienne des médicaments et des technologies de la santé . . 6

III.2 Examen de la documentation . . . . . . . . . . . . . . . . . . . . . . . . .

III.3 Réunion du Groupe de travail sur l'influenza avec les spécialistes de la santé animale . . . . . . . . . . 6

IV. Résultats . . . . . . . . . . . . . . . . . . . . . . . . .

IV.1 Rapport d'intervention rapide de l'Agence canadienne des médicaments et des technologies de la santé . . 7

IV.2 Examen de la documentation du Groupe de travail sur les indicateurs de santé publique . . . . . . . . . . 7

IV.2.1 Virus de la grippe aviaire chez les personnes exposées dans le cadre de leur travail à la volaille ou aux oiseaux sauvages. . . . . . . . . . . . . . . . . . . . . . . . . . .

IV.2.2 Transmission secondaire du virus de la grippe aviaire $\ldots \ldots \ldots \ldots \ldots$

IV.2.3 Virus de la grippe porcine chez les personnes exposées aux porcs dans le cadre de leur travail ......8

IV.2.4 Transmission secondaire du virus de la grippe porcine $\ldots \ldots \ldots \ldots$

IV.2.5 Vaccination antigrippale chez les personnes exposées dans le cadre de leur travail . . . . . . . . 9

IV.2.6 Recommandations actuelles concernant la vaccination antigrippale chez les personnes exposées dans le cadre de leur travail . . . . . . . . . . . . . . . . . . . . . . . .

IV.3 Réunion du Groupe de travail sur l'influenza avec les spécialistes de la santé animale . . . . . . . . . 10

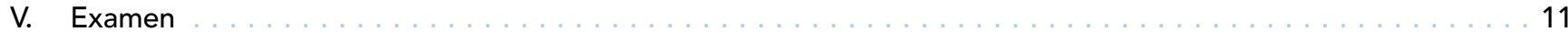

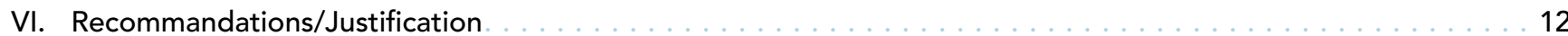

VI.1 Ouvriers avicoles. . . . . . . . . . . . . . . . . . . . . . . . . . .

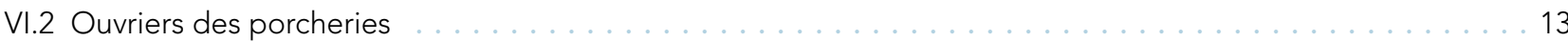

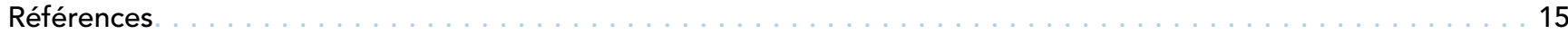

Annexe $\mathrm{A}$ : Résumé des données probantes pour la recommandation du CCNI . . . . . . . . . . . . . . 19

Annexe $B$ : Recommandations nationales concernant la vaccination antigrippale saisonnière pour les ouvriers exposés aux animaux dans le cadre de leur travail 


\section{Résumé}

Au milieu de l'année 2012, en réponse à l'émergence de plusieurs souches de la variante de la grippe porcine chez les humains aux États-Unis (H3N2v, H1N1v, H1N2v) et au Canada (H1N1v), l'Agence de la santé publique du Canada (ASPC) a demandé au Groupe de travail sur l'influenza (GTI) du Comité consultatif national de l'immunisation (CCNI) d'examiner une recommandation préconisant la vaccination des personnes exposées dans le cadre de leur travail aux porcs et aux volailles. Au Canada, le processus d'élaboration du CCNI concernant les recommandations sur la vaccination antigrippale tient compte d'un vaste éventail d'études et de données afin de présenter des recommandations fondées sur des données probantes dans le cadre de l'évaluation de l'innocuité et de l'efficacité des vaccins pour humains. Le jugement professionnel, l'expérience clinique et l'analyse globale du risque influent également sur les recommandations. Pour ce qui est de préoccupations concernant la santé animale, le lecteur aura intérêt à consulter les ressources pertinentes.

Pour éclairer la présente analyse, I'ASPC et le GTI du CCNI ont adopté diverses méthodes d'exploration du sujet, dont les données scientifiques, les pratiques exemplaires et I'opinion d'experts. Le présent rapport décrit le processus, les études et les données employées par le CCNI pour formuler sa recommandation sur la vaccination saisonnière des ouvriers des porcheries et des poulaillers. Font partie des données probantes:

- Un examen rapide effectué par l'Agence canadienne des médicaments et des technologies de la santé intitulé Influenza Vaccination for Prevention of Cross-species Infection: A Review of the Clinical Evidence;

- Un examen de la documentation mené afin d'établir la prévalence et le risque de transmission hétérospécifique de la grippe A chez l'animal;

- Une réunion avec les spécialistes de la santé animale afin de comprendre les pratiques actuelles de vaccination des ouvriers des porcheries et des poulaillers, les mesures de biosécurité utilisées dans l'industrie et le risque de la transmission hétérospécifique de la grippe.

\section{I.1 APERÇU DES GRANDES CONCLUSIONS}

- On n'a relevé aucune étude portant sur l'efficacité de la vaccination des ouvriers des porcheries et des poulaillers sur le réassortiment génétique du virus grippal.
- La transmission de la grippe aviaire ou porcine des populations animales aux humains exposés dans le cadre de leur travail a lieu, mais peu fréquemment.

- Les ouvriers exposés dans le cadre de leur travail sont plus susceptibles à la séropositivité de la grippe aviaire ou porcine que les personnes non exposées.

- Le potentiel d'une transmission limitée interhumaine existe entre les ouvriers infectés et les membres du ménage non exposés.

- Un vaste éventail de taux de vaccination contre la grippe saisonnière existe chez les ouvriers.

- La majorité des vétérinaires canadiens pratiquant la médecine porcine font partie d'associations professionnelles qui ont des énoncés de position préconisant la vaccination saisonnière; ils connaissent, pour la plupart, ces recommandations.

- Les exploitations agricoles canadiennes ont des mesures de biosécurité rigoureuses comme moyen principal pour prévenir la grippe aviaire ou porcine.

\section{I.2 APERÇU DES LIMITES PRINCIPALES DE L'EXAMEN DE LA DOCUMENTATION}

- Un grand degré d'hétérogénéité entre les études a nui à la comparabilité;

- Absence de protocoles d'essai standards pour la séroréaction aux souches non humaines non liées au H5N1:

- Les études ont utilisé des seuils de coupure de titres différents pour déceler une réponse positive;

- Le potentiel d'affaiblissement de l'immunité ou de protection croisée a une incidence sur la détection;

- Réactivité croisée entre le virus de la grippe porcine, aviaire et humaine;

- Un bon nombre d'études étaient des enquêtes transversales de séroprévalence:

- La prévalence des virus de la grippe aviaire ou porcine dans les populations animales ou dans la région n'était pas connue en général ou sa présence n'était pas confirmée;

- Certaines études ont mis sur pied des groupes témoins, mais il y avait des problèmes de comparabilité. 


\section{I.3 CONCLUSIONS}

Après analyse du corpus de données disponibles, le CCNI a décidé à l'unanimité d'adopter les recommandations suivantes:

- «Le CCNI conclut que les données probantes sont actuellement insuffisantes pour recommander précisément la vaccination antigrippale systématique aux ouvriers des porcheries (recommandation du CCNI de catégorie I); cependant, le CCNI encourage I'administration du vaccin antigrippal chez tous les Canadiens âgés de 6 mois et plus. »

\section{Introduction}

On considère le réassortiment génétique des virus de la grippe A provenant de diverses espèces animales comme mécanisme de propagation des virus de la grippe ayant un potentiel pandémique. Les virus de la grippe humaine et les virus de la grippe d'origine aviaire et porcine circulent exclusivement au sein de leurs espèces respectives, de façon générale. Cependant, les virus de la grippe ont la capacité d'infecter des espèces autres que leur hôte indigène et un potentiel de transmission dans celle-ci. Les virus de la grippe A sont classés selon deux protéines de surface : I'hémagglutinine (HA) et la neuraminidase (NA). Dans une analyse statistique de 3874 séquences de neuraminidase (N1-N9) pleine longueur, Yan et coll. (2010) ${ }^{1}$ ont découvert que la variation intraspécifique est plus élevée chez certaines espèces hôtes que la variation interspécifique. Bien qu'un certain nombre des sous-types de virus ne semble pas transmissible entre les espèces, certains sous-types ont une barrière faible, alors que $d^{\prime}$ autres n'ont pratiquement aucune barrière entre les espèces, dans la nature et en laboratoire.

\section{II.1 ÉPIDÉMIOLOGIE DES VIRUS DE LA GRIPPE D'ORIGINE ANIMALE}

Les humains travaillant avec des animaux vivants ou morts lesquels sont aussi des réservoirs pour la grippe, notamment la volaille et le porc, sont vraisemblablement plus à risque d'infecter les animaux avec lesquels ils travaillent et d'être infectés par eux en raison du degré élevé d'interaction. Le rôle des virus de la grippe d'origine animale causant la maladie chez les humains est reconnu depuis longtemps; cependant, la fréquence avec laquelle les virus de la grippe animale se transmettent aux humains ou vice versa n'est pas claire. La plupart des systèmes de
- «Le CCNI continue de recommander l'immunisation contre la grippe saisonnière chez les personnes en contact direct, durant les activités d'abattage, avec de la volaille infectée par le virus de la grippe aviaire (recommandation du CCNI de catégorie I); cependant, le CCNI encourage l'administration du vaccin antigrippal chez tous les Canadiens âgés de 6 mois et plus. »

Ces recommandations se trouvent dans la Déclaration sur la vaccination antigrippale pour la saison 2013-2014.

surveillance actuels ne sont pas programmés pour détecter les maladies asymptomatiques ou bénignes chez les humains causées par les virus de la grippe humaine ou animale. En outre, la grippe porcine n'est pas une maladie à déclaration obligatoire au Canada, et aucun système surveillance national n'existe pour détecter précisément la grippe d'origine porcine chez les humains. En dépit de cette lacune, les examens systématiques effectués chez les animaux et les humains peuvent détecter les souches de grippe émergentes, dont certaines ont suscité beaucoup d'intérêt.

L'influenza aviaire a des répercussions sur le plan économique et de la santé. Sont classés comme virus de I'influenza aviaire à déclaration obligatoire (IADO) les virus des sous-types $\mathrm{H} 5$ et $\mathrm{H} 7$, ainsi que tout virus de l'influenza aviaire hautement pathogène (IAHP). Quant aux virus de I'influenza aviaire faiblement pathogènes (IAFP), ils sont associés à des maladies bénignes ou non visibles chez la volaille. Les virus de I'IAHP peuvent causer des maladies graves et entraîner des taux de mortalité élevés dans les troupeaux de volaille. Des mesures d'abattage rigoureuses sont généralement prises pour lutter contre ces virus, ce qui peut être dévastateur pour les activités avicoles. À I'heure actuelle, le virus de la grippe aviaire le plus prolifique est le virus H5N1, hautement pathogène. Depuis son apparition en 1997, il a entraîné la mort de 371 personnes sur 622 cas humains confirmés ${ }^{2}$ (au 12 mars 2013) et a fait l'objet d'une haute surveillance comme souche de grippe ayant un potentiel pandémique. Jusqu'ici, cependant, il n'a pas encore acquis une capacité de transmission efficace d'humain à humain, bien qu'il continue d'avoir un taux élevé de cas de mortalité lorsqu'il est contracté par les humains. 
La surveillance des virus de la grippe aviaire à déclaration obligatoire est bien établie. Le Système canadien de surveillance de l'influenza aviaire à déclaration obligatoire (SCSIADO) est une initiative conjointe entre le gouvernement, l'industrie et les agriculteurs afin de prévenir, de détecter et d'éliminer les sous-types de virus de la grippe aviaire $\mathrm{H} 5$ et $\mathrm{H} 7$. Le SCSIADO respecte les lignes directrices émises par l'Organisation mondiale de la santé animale (OIE) sur la déclaration obligatoire de la grippe aviaire ainsi que les exigences commerciales établies par l'Union européenne ${ }^{3}$.

Contrairement au virus de la grippe aviaire, le virus de la grippe porcine cause généralement peu de décès dans la population porcine, mais peut y provoquer des taux élevés de maladies. Le porc présente un intérêt particulier en ce qui concerne la transmission hétérospécifique de la grippe, étant donné qu'il possède des récepteurs à l'intérieur des voies respiratoires qui le rendent susceptible de contracter les virus de la grippe humaine et aviaire. La transmission de la grippe entre les porcs et les humains est connue pour se produire, à l'instar de la transmission entre la volaille et le porc. Le porc est considéré historiquement comme un " mélangeur » idéal pour la production de nouveaux virus. Cependant, des études récentes indiquent que d'après les récepteurs uniquement, les porcs et les humains sont tous les deux susceptibles de servir de mélangeur pour le réassortiment viral ${ }^{4,5}$.

Au Canada, il n'existe aucun programme de surveillance fédéral pour détecter la grippe chez les porcs, et les programmes de surveillance provinciaux et territoriaux peuvent varier d'un endroit à l'autre. Un programme de surveillance volontaire de la grippe porcine a été établi aux États-Unis en 2008 et est dirigé par le département de l'agriculture américain en collaboration avec les États et l'industrie. Du 1er octobre 2010 au 31 juillet 2012, le programme a testé 12662 échantillons prélevés à partir de 3766 soumissions de laboratoire de diagnostic liées au porc (plusieurs échantillons pour chacune des soumissions) et a constaté 1488 cas de séropositivité pour les infections par la grippe $A^{6}$.

\section{II.2 RISQUE PANDÉMIQUE}

Une pandémie de grippe est un événement imprévisible et récurrent dont les répercussions sur la population sont importantes ${ }^{7}$. Elle a lieu lorsqu'un nouveau virus de la grippe transmissible chez les humains se propage largement dans le monde et contre lequel il existe peu de protection immunologique. Depuis le XVIe siècle, les pandémies se sont produites à des intervalles de 10 à 50 ans $^{8}$. On ne peut prédire quand une nouvelle souche de grippe surgira, quand elle deviendra une préoccupation pandémique et quelle sera son ampleur. La souche de la grippe H1N1 de la pandémie de 2009 était similaire antigéniquement aux virus $\mathrm{H} 1 \mathrm{~N} 1$ circulant chez les porcs en Amérique du Nord, et elle était distincte des virus de la grippe saisonnière humaine H1N1. Son génome comportait un réassortiment génétique des virus de la grippe A d'origine porcine, humaine et aviaire?. Cette donnée illustre le rôle joué par le réassortiment génétique dans l'évolution des souches de grippe pandémique.

\section{II.3 OBJECTIF}

Le présent examen vise à évaluer le corpus de données qui existe sur le risque et la prévalence de la transmission hétérospécifique de la grippe aux humains et à partir des humains. Il comprend un rapport d'intervention rapide de l'Agence canadienne des médicaments et des technologies de la santé, un examen de la documentation sur la transmission hétérospécifique de la grippe et une réunion avec les membres du Groupe de travail sur la grippe aviaire issus du comité conjoint des médecins hygiénistes en chef et des vétérinaires en chef. 


\section{Méthodologie}

\section{III.1 RAPPORT D'INTERVENTION RAPIDE DE L'AGENCE CANADIENNE DES MÉDICAMENTS ET DES TECHNOLOGIES DE LA SANTÉ}

En février 2012, I'ASPC a demandé à l'Agence canadienne des médicaments et des technologies de la santé d'examiner des données cliniques concernant l'efficacité de la vaccination des ouvriers travaillant avec des animaux afin de réduire le risque d'infection grippale hétérospécifique chez les humains et le risque de co-infection grippale humaine et animale. Deux questions de recherche se sont posées:

1. Quelles sont les données cliniques sur l'efficacité de la vaccination des ouvriers travaillant avec des animaux afin de réduire le risque d'infection grippale hétérospécifique chez les humains?

2. Quelles sont les données cliniques sur l'efficacité de la vaccination des ouvriers travaillant avec des animaux afin de réduire le risque de co-infection par la grippe humaine et animale?

Une recherche limitée de la documentation a été menée à I'aide de PubMed, de la bibliothèque Cochrane, de bases de données du Centre for Reviews and Dissemination de l'Université de York, d'organismes canadiens et internationaux de premier plan de la technologie de la santé et de la recherche ciblée sur Internet. Tous les types d'études ont été examinés et la recherche s'est limitée à

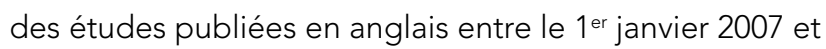
le 11 janvier 2012. Pour une méthodologie plus détaillée, veuillez vous reporter au rapport ${ }^{10}$.

\section{III.2 EXAMEN DE LA DOCUMENTATION}

Deux recherches ont été menées dans chacune des quatre bases de données suivantes: Medline, Embase, Global Health et Agricola, pour la documentation publiée en anglais jusqu'au 3 juillet 2012. La première recherche portait sur l'infection grippale porcine ou aviaire chez les ouvriers agricoles qui travaillaient avec le bétail et la deuxième, sur l'infection grippale hétérospécifique. Un total de 273 et de 1163 articles sont issus de la première et de la deuxième recherche, respectivement. Les recherches sont restées vastes, pour permettre d'évaluer l'ampleur du corpus de données sur le sujet. À la suite de cette évaluation, d'autres critères ont été appliqués pour réduire l'étendue de l'examen. Les critères d'inclusion des articles présentant un intérêt étaient ceux qui visaient une infection grippale hétérospécifique transmise aux humains et provenant des humains qui travaillent avec des animaux vivants ou morts ou qui les élèvent. Les articles exclus étaient ceux qui ne comprenaient pas de recherche originale, d'étude expérimentale sur l'infection grippale, d'analyse pour les souches grippales indigènes à la population étudiée (p. ex. la grippe aviaire chez la volaille, la grippe humaine chez les humains) ou ceux publiés avant 1997. Veuillez consulter l'Annexe A pour obtenir les tableaux de données.

Un examen rapide se limitant à la langue française et anglaise a aussi été mené pour déterminer les pays qui font actuellement une recommandation explicite à I'intention des ouvriers travaillant avec les animaux pour qu'ils reçoivent une vaccination antigrippale saisonnière (Annexe B).

\section{III.3 RÉUNION DU GROUPE DE TRAVAIL SUR L'INFLUENZA AVEC LES SPÉCIALISTES DE LA SANTÉ ANIMALE}

Le Groupe de travail sur l'influenza a tenu une réunion spéciale en décembre 2012 afin de discuter des pratiques actuelles de vaccination des ouvriers des porcheries et des poulaillers, des mesures de biosécurité utilisées dans I'industrie et du risque de transmission hétérospécifique de la grippe avec les membres du Groupe de travail sur la grippe aviaire issus du comité conjoint des médecins hygiénistes en chef et des vétérinaires en chef. Veuillez vous reporter à la section examen pour obtenir des renseignements supplémentaires. 


\section{Résultats}

\section{IV.1 RAPPORT D'INTERVENTION RAPIDE DE L'AGENCE CANADIENNE DES MÉDICAMENTS ET DES TECHNOLOGIES DE LA SANTÉ}

La recherche de la documentation a donné lieu à 219 citations dont 215 ont été exclues après lecture des titres et des citations. Quatre articles potentiellement pertinents ont subi un examen en texte intégral, tandis qu'un article a été recensé dans la documentation parallèle. Aucun des cinq articles ne répondait aux critères d'inclusion. Quelques-unes des études se sont intéressées aux conséquences des vaccins antigrippaux sur la population générale, les bénévoles en santé, les enfants et les personnes âgées ou les travailleurs de la santé, mais aucune ne s'est intéressée aux ouvriers travaillant avec les animaux.

\section{IV.2 EXAMEN DE LA DOCUMENTATION DU GROUPE DE TRAVAIL SUR LES INDICATEURS DE SANTÉ PUBLIQUE}

Un total de 44 articles remplissant les critères d'inclusion et d'exclusion ont été sélectionnés aux fins d'examen. En tout, 31 articles ont évalué la séroprévalence du virus de la grippe aviaire chez les personnes exposées dans le cadre de leur travail à des troupeaux de volailles ou d'oiseaux sauvages et 13 articles ont évalué le virus de la grippe porcine chez les personnes exposées dans le cadre de leur travail à des porcs. Un large éventail de personnes pouvant être exposées dans le cadre de leur travail au virus de la grippe aviaire ou porcine ont été évaluées, notamment les agriculteurs artisanaux, les agriculteurs ou les ouvriers travaillant dans des exploitations agricoles commerciales, les préposés à l'abattage ou les abatteurs, les usines de transformation de la viande, les vétérinaires, les analystes de laboratoire, les chercheurs, les employés du gouvernement ${ }^{11}$, les pompiers ${ }^{11}$, les manipulateurs d'oiseaux migrateurs et les bagueurs d'oiseaux. Chez les personnes exposées au virus de la grippe aviaire et porcine, les indications immunologiques d'infection hétérospécifique n'ont pas été détectées à une fréquence élevée. Des taux de réponse immunitaire faibles à la grippe animale dans la population étudiée ont été détectés dans la plupart des études, quoique certains aient pu être le résultat d'une réactivité croisée à l'exposition aux grippes humaines. Un petit nombre d'études consistait aussi à évaluer les membres du ménage des personnes atteintes des virus confirmés de la grippe aviaire ou porcine, en tant que participants à l'étude ou aux groupes témoins.

\section{IV.2.1 Virus de la grippe aviaire chez les personnes exposées dans le cadre de leur travail à la volaille ou aux oiseaux sauvages}

Des 31 articles évaluant la séroprévalence du virus de la grippe aviaire chez les humains, 8 portaient sur la séroprévalence de ce virus chez les équarrisseurs, les abatteurs ou les personnes recueillant des oiseaux morts ${ }^{11-17}$. Aussi, 18 articles portaient sur les ouvriers des poulaillers commerciaux; 7 , sur les ouvriers des poulaillers non commerciaux (p. ex. les agriculteurs artisanaux) et 4, sur d'autres ouvriers, dont les bagueurs d'oiseaux ${ }^{18}$, les manipulateurs $d^{\prime}$ oiseaux migrateurs ${ }^{19}$, les pompiers ${ }^{11}$ et les employés du gouvernement ${ }^{11}$ travaillant dans le domaine de l'abattage.

Au nombre des 18 articles traitant des ouvriers des poulaillers commerciaux, 8 catégorisaient une personne séropositive lorsque les titres d'anticorps étaient au moins $\geq 1: 10$. Huit autres tenaient compte de la séropositivité lorsque les titres étaient au moins $\geq 1: 80$. Un article ne divulguait pas les conditions de séropositivité et un autre article recueillait simplement de l'information sur les symptômes. II importe d'observer la différence dans les seuils de titres utilisés, car, en ce moment, un titre $\geq 1: 80$ est recommandé pour évaluer une infection potentielle par le virus H5N1. II n'y a aucune autre recommandation sur les autres souches de grippe aviaire, bien que certains articles aient employé les recommandations sur le virus H5N1 comme ligne de conduite pour leurs essais de laboratoire. Certaines études ont utilisé un seuil $\geq 1: 80$, mais on les a combinées avec les études égales à 1:80 aux fins de comparaison.

Globalement, la séroprévalence du virus de la grippe aviaire était généralement faible ( $<1 \%$ des participants), mais une activité sérologique a été relevée dans la majorité des études. Deux articles utilisant un seuil de titre d'anticorps $\leq 1: 80$ n'ont découvert aucune preuve d'activité sérologique. Quatre articles utilisant un seuil $\geq 1: 80$ ont fait état de participants ayant des taux d'activité sérologique faibles, mais aucun ne remplissait les conditions de séropositivité. 
Dans un petit nombre d'études évaluant les ouvriers avicoles et les préposés à l'abattage, ces derniers formaient la majorité des cas séropositifs. Alizadeh et coll. (2009) ont découvert que la séropositivité du virus de la grippe aviaire chez les ouvriers d'abattoirs était 2,09 fois plus élevée que chez les ouvriers des poulaillers $(51,6 \%$ contre 24,6\%) parmi les 48 ouvriers séropositifs sur 127 visant le H9N2 (titres $\geq 1: 20)^{12}$. Durant une éclosion du H5N1 en Corée du Sud, 9 cas positifs sur 2512 (titres $\geq 1: 80$ ) étaient des préposés à l'abattage ${ }^{15}$. Dans une étude de Schultsz et coll. (2009), 3 préposés à l'abattage sur 317 travaillant dans l'abattage depuis plus d'un an avaient des titres de microneutralisation (MN) de 1:20, de 1:40 et de 1:200. Aucun des 183 ouvriers avicoles n'affichait de titre positif contre le H5N1 ${ }^{17}$. Toutefois, une étude dans le Cambodge rural menée par Vong et coll. (2006) a indiqué les poulets abattus comme facteur de risque insignifiant de séropositivité après vérification des expositions, notamment le nettoyage des cages ou des stalles, la manipulation de la volaille vivante, l'achat de la volaille vivante et le nettoyage des plumes de volaille ${ }^{20}$.

Parmi les études évaluant les ouvriers des poulaillers non commerciaux (p. ex. les agriculteurs artisanaux), quatre sur sept ont découvert de faibles taux d'activité sérologique liés au virus de la grippe aviaire, mais les trois autres n'en ont pas découvert.

Les quatre études évaluant le virus de la grippe aviaire chez les autres ouvriers (p. ex. non agricoles) ont affiché une activité sérologique contre ce virus chez un petit nombre de leurs participants.

\section{IV.2.2 Transmission secondaire du virus de la grippe aviaire}

Quatre des trente études sur la grippe aviaire ont testé des contacts du ménage des ouvriers en vue de détecter une infection potentielle au virus de la grippe aviaire. Parmi 28 membres de la famille de 5 cas confirmés d'infection par le virus $\mathrm{H} 5 \mathrm{~N} 1$, une seule personne a produit un échantillon positif par test de microneutralisation ${ }^{21}$. Dans une autre étude, 56 des 62 membres du ménage (qui n'ont pas été exposés à la volaille) des ouvriers avicoles atteints du virus $A$ (H7N7) confirmé ont présenté un échantillon de sérum au moins trois semaines après le diagnostic du premier cas. Parmi les 62 personnes, 8 se sont plaintes de problèmes de santé et 2 répondaient aux définitions de cas pour la conjonctivite et le syndrome grippal. Parmi les 56 personnes remettant un échantillon de sérum,
33 avaient des anticorps détectables contre le $\mathrm{H}^{22}$. Un échantillon d'ouvriers provenant d'une enquête sur la santé agricole menée en lowa a utilisé les épouses non exposées des ouvriers agricoles ruraux exposés à la volaille comme groupe de comparaison. Au cours d'une période de 24 mois, 3 personnes dans le groupe témoin ont affiché un niveau de titre $\geq 1: 20$ pour les virus $\mathrm{H} 4, \mathrm{H} 5$, $\mathrm{H} 6$ et $\mathrm{H} 9$. Une personne avait un titre $\geq 1: 80$ pour le $\mathrm{H}^{23}$. La surveillance des éclosions au cours d'une éclosion du H7 dans les Pays-Bas en 2003 a confirmé la présence du virus $A(H 7)$ dans trois contacts du ménage d'un ouvrier avicole ou d'un aviculteur ${ }^{24}$.

\section{IV.2.3 Virus de la grippe porcine chez les personnes exposées aux porcs dans le cadre de leur travail}

Treize articles sur quarante-trois ont évalué la séroprévalence du virus de la grippe porcine (SwIV) chez les humains. Onze études ont été menées chez des ouvriers d'exploitations agricoles commerciales et deux études ont été menées dans des exploitations agricoles communautaires. Des personnes séropositives ont été détectées dans toutes les études, et Gray et coll. (2007) ont pu isoler le virus de la grippe porcine chez une personne symptomatique ${ }^{25}$. Le nombre de personnes séropositives à au moins un virus de la grippe porcine variait entre 1 et 2 personnes jusqu'à 47 personnes, selon l'étude.

Beaudoin et coll. (2010) ont comparé les employés de deux grandes fermes porcines semblables où une des exploitations était connue pour abriter un porc séropositif pour le H2N3. Quatre participants étaient séropositifs pour le H2N3, dont un seul travaillait dans l'exploitation exposée. On a présumé que la séropositivité pouvait ne pas avoir de lien avec l'exposition récente. Trois des quatre participants étaient nés avant 1968, et celui travaillant dans l'exploitation agricole exposée était né en 1949. L'activité sérologique a pu être le résultat de la réactivité croisée au virus de la grippe humaine H2N3 en circulation précédemment.

Même si les personnes exposées aux porcs n'ont pas produit de réponse sérologique plus grande, Gerloff et coll. (2011) ${ }^{26}$ n'ont pas décelé une différence significative entre les réponses sérologiques de personnes en santé ayant une exposition professionnelle passée ou présente aux porcs et les échantillons de contrôle de sérum de la population générale. 


\section{IV.2.4 Transmission secondaire du virus de la grippe porcine}

Deux articles ont évalué la transmission potentielle du virus de la grippe porcine au ménage depuis les ouvriers. En utilisant un échantillon des ouvriers de porcheries et de leurs épouses non exposées tiré de l'enquête sur la santé agricole en lowa, les chercheurs ont constaté que les épouses étaient à un risque accru de contracter le virus de la grippe porcine H1N1 à comparer aux témoins universitaires non exposés, avec un taux de risque ajusté (TRA) de 28,2 (IC à $95 \%: 6,1$; 130,1). Les ouvriers de porcheries avaient un TRA de 54,9 (IC à $95 \%: 12,0 ; 232,6)^{25}$. Robinson et coll. $(2007)^{27}$ ont évalué les membres d'une exploitation agricole communautaire où un enfant en bas âge avait été hospitalisé en raison d'un virus de grippe porcine (confirmé). Huit membres de trois ménages (y compris quatre membres du ménage du patient de référence) étaient séropositifs (titres $\geq 32$ ). La plupart n'avaient pas été exposés aux porcs ou avaient subi moins d'une heure d'exposition par semaine. Un des dix échantillons de sérum porcin était séropositif pour la même souche ayant infecté le patient de référence ${ }^{27}$.

\section{IV.2.5 Vaccination antigrippale chez les personnes exposées dans le cadre de leur travail}

Des renseignements sur les antécédents de vaccination ont été recueillis dans 22 des études, et les résultats variaient entre les ouvriers ayant reçu le vaccin antigrippal saisonnier au cours de la dernière année et ceux n'ayant jamais reçu de vaccin antigrippal saisonnier. Une étude posait une question précise sur la réception du vaccin antigrippal porcin de 1976. Les taux de vaccination variaient de 0 à $60 \%$ environ dans la population étudiée. Dans les groupes témoins, les taux de vaccination étaient aussi élevés que $76 \%^{18}$. La grande variation dans les taux de vaccination peut être attribuée à des facteurs comme I'accès aux vaccins, I'habitation en région rurale ou urbaine, la pratique d'une agriculture artisanale ou le travail dans une exploitation agricole commerciale.

\section{IV.2.6 Recommandations actuelles concernant la vaccination antigrippale chez les personnes exposées dans le cadre de leur travail}

Depuis un examen rapide se limitant à la langue française et anglaise, un petit nombre de pays ont des recommandations nationales sur la vaccination antigrippale saisonnière qui mentionnent explicitement l'exposition professionnelle aux animaux (Annexe B).

Au Canada, le CCNI recommande que les gens qui sont en contact direct avec de la volaille infectée au cours des activités d'abattage, comme les préposés à l'abattage, les vétérinaires chargés de la supervision et les inspecteurs, reçoivent la vaccination antigrippale. L'Agence canadienne d'inspection des aliments ( $\mathrm{ACIA}$ ) utilise la déclaration plus générale du CCNI qui incite tous les Canadiens en santé âgés de six mois et plus à recevoir le vaccin antigrippal saisonnier, dans le but d'encourager toutes les personnes travaillant dans le système de production alimentaire (p. ex. les producteurs et leur famille, les ouvriers agricoles, les vétérinaires, le personnel du service agricole, les gens visitant les porcheries) à recevoir le vaccin comme mesure de biosécurité.

Aux États-Unis, les Centers for Disease Control and Prevention (CDC) ont émis une déclaration en 2010 présentant une recommandation universelle en faveur de la vaccination antigrippale saisonnière qui formule explicitement que les personnes chargées d'intervenir en cas d'éclosions de la grippe aviaire chez la volaille reçoivent un vaccin antigrippal saisonnier ${ }^{28}$. La mise à jour de 2012 de la déclaration n'a pas fait état de cette recommandation ${ }^{29}$. En raison de l'activité récente impliquant la variante du virus H3N2 de 2011, les CDC ont émis une directive provisoire à l'intention des ouvriers travaillant dans des porcheries commerciales et ont recommandé la vaccination antigrippale saisonnière en vue de réduire le risque de transmission des virus grippaux saisonniers des personnes malades aux porcs ${ }^{30}$.

En Australie, le guide d'immunisation recommande la vaccination antigrippale saisonnière pendant une activité de grippe aviaire confirmée pour les personnes travaillant dans l'industrie avicole commerciale ou dans l'abattage. Toutefois, cette recommandation n'est pas énoncée dans les déclarations annuelles sur la grippe saisonnière produites par l'Australian Technical Advisory Group on Immunisation (ATAGI). 
Le ministère de la Santé de Hong Kong recommande le vaccin antigrippal saisonnier pour les aviculteurs et, en outre, pour les éleveurs de porcs et les personnes dans I'industrie de l'abattage des porcs.

Au Royaume-Uni, au début de la saison 2006-2007, un programme annuel de la grippe saisonnière a été mis en place pour les ouvriers avicoles. Cependant, en raison des difficultés à exploiter le programme et du faible taux de vaccination, ce programme a pris fin après la saison de 2010-2011. La recommandation de faire vacciner ces ouvriers, considérés comme groupe de faible priorité, a aussi été annulée. Quant aux ouvriers de porcheries, ils ont été évalués en 2006 et en 2009 à titre de groupe cible potentiel pour la vaccination, mais aucune recommandation n'a été proposée par le comité conjoint sur la vaccination et l'immunisation en raison de données probantes limitées.

Le nombre de pays échantillonnés était limité par des restrictions linguistiques concernant la recherche. Une analyse a été menée par le Vaccine European New Integrated Collaboration Effort Project, portant sur des politiques nationales de vaccination antigrippale dans I'Union européenne, en Norvège et en Islande en $20099^{31}$. Parmi les 27 pays évalués, 13 (48\%) recommandaient le vaccin antigrippal saisonnier pour les ouvriers dans l'industrie avicole et 9 (33\%) recommandaient la vaccination pour les personnes dans les services vétérinaires. Dans un deuxième sondage, auquel ont répondu 26 pays, 4 pays (15\%) ont recommandé que les familles qui élèvent de la volaille reçoivent le vaccin antigrippal. Toutefois, les recommandations sont soumises à des changements constants, et les auteurs ont observé que plusieurs pays avaient modifié leurs politiques de vaccination depuis que les premiers sondages avaient été menés.

\section{IV.3 RÉUNION DU GROUPE DE TRAVAIL SUR L'INFLUENZA AVEC LES SPÉCIALISTES DE LA SANTÉ ANIMALE}

Le Groupe de travail sur l'influenza a tenu une réunion spéciale en décembre 2012 afin de discuter des pratiques actuelles de vaccination des ouvriers des porcheries et des poulaillers, des mesures de biosécurité utilisées dans l'industrie et le risque de transmission hétérospécifique de la grippe avec les membres du Groupe de travail sur la grippe aviaire issus du comité mixte des médecins hygiénistes en chef et des vétérinaires en chef. Voici un résumé de la discussion ${ }^{32,33}$.
La plupart des vétérinaires canadiens pratiquant la médecine porcine font partie d'associations professionnelles qui ont des énoncés de position préconisant la vaccination saisonnière; ils connaissent majoritairement ces recommandations. Le taux de vaccination, cependant, demeure inconnu. Le Conseil canadien de la santé porcine a publié un communiqué encourageant le personnel des porcheries et les vétérinaires à se faire vacciner. II a tenu une clinique de vaccination à sa réunion d'octobre 2012, et certains ouvriers canadiens des porcheries sont conscients que ce conseil encourage la vaccination antigrippale.

Bon nombre de grandes porcheries dans l'industrie porcine exigent que leur personnel soit vacciné contre la grippe, mais il est difficile d'imposer la vaccination, donc, en général, elles font des recommandations, offrent des cliniques de vaccination et essaient d'informer le personnel. Le fait que les humains peuvent être une source d'infection grippale pour les porcs a été plus largement accepté après la pandémie de H1N1. Certaines fermes porcines n'autoriseront pas les gens à entrer dans les porcheries s'ils présentent les symptômes d'un syndrome grippal.

Le mode d'interaction entre les humains et les porcs au Canada est légèrement différent de celui qui a cours aux États-Unis. Au Canada, l'industrie porcine et la population humaine sont plus réduites, et il y a moins de foires agricoles. Par conséquent, il y a moins d'interactions entre les humains et les porcs en ce qui concerne le grand public. Les fermes canadiennes possèdent généralement des mesures de biosécurité plus rigoureuses, et la majorité des porcs sont confinés à l'intérieur toute l'année en raison d'une température plus froide. Dans de nombreuses régions, les porcs sont vaccinés, mais pas sur une base annuelle en raison du coût. Les souches de grippe porcine n'ont pas tendance à changer rapidement d'une année à l'autre dans de nombreuses régions du Canada.

Cependant, dans les régions où un nombre élevé de porcs sont produits dans les grands systèmes d'exploitation, les souches grippales changent rapidement, ce qui nécessite souvent une vaccination autogène pour prévenir les symptômes. Il s'agit d'un scénario plus courant aux États-Unis, où l'industrie de la production porcine est beaucoup plus importante. Les vaccins porcins présentent les mêmes défis d'efficacité que les vaccins fabriqués pour les humains; ils n'apportent pas de protection contre $d^{\prime}$ autres souches de virus grippaux qui peuvent atteindre le troupeau. Dans les régions où les élevages sont plus éparpillés, la transmission du virus de la grippe porcine est moins élevée que dans les régions où les élevages sont plus près les uns des autres. Il y a de grandes variations régionales concernant la distance entre les élevages à l'échelle des États-Unis et du Canada. 
La biosécurité est également le principal moyen de prévention de la grippe aviaire. Cette grippe est à déclaration obligatoire au Canada. La surveillance et le pouvoir sont en place pour intervenir en cas de détection d'une éclosion, peu importe son degré de pathogénicité. Certains aviculteurs ont leur propre recommandation exigeant la vaccination d'un ouvrier avant qu'il commence à travailler avec la volaille, mais ces recommandations ne sont pas obligatoires. Contrairement au porc, les virus de la grippe ne sont pas systématiquement découverts dans les poulaillers commerciaux au Canada. Les oiseaux ne sont pas aussi susceptibles d'être infectés par les virus de la grippe humaine en raison de différences entre les récepteurs aviaires et mammifères. Les mammifères (p. ex. porcs, furets, chiens, chats) sont plus susceptibles de partager les virus de la grippe avec les humains.

\section{Examen}

Le rapport d'intervention rapide commandé par l'Agence canadienne des médicaments et des technologies de la santé s'appuyait sur une recherche de documentation limitée et ne constituait pas un examen exhaustif et systématique. II offrait toutefois un résumé sur l'absence actuelle de données probantes concernant la vaccination antigrippale des ouvriers travaillant avec les animaux en vue de prévenir l'infection hétérospécifique. Comme il n'existe pas de données probantes, on ne peut tirer aucune conclusion sur l'efficacité de la vaccination dans ce groupe d'ouvriers.

Bien que la transmission de la grippe aviaire et porcine aux humains qui s'occupent de ces animaux soit recensée, en raison de certaines limites de ces études, il est difficile de déterminer la véritable ampleur du fardeau de la transmission hétérospécifique.

L'une des limites de l'examen de la documentation sur le sujet est le fait qu'il n'existe aucun protocole d'essai standard pour évaluer la réponse immunitaire humaine aux souches de grippe ne s'étant pas adaptées à une transmission interhumaine, sauf pour le H5N134. II s'agit d'un problème de taille puisque cela nuit à la comparabilité des études, étant donné que les auteurs adoptent différentes
Il existe aussi un segment croissant de la population humaine, au Canada et aux États-Unis, qui élèvent des porcs et de la volaille à plus petite échelle, en dehors de l'industrie commerciale. Souvent appelés « producteurs artisanaux ", ils vendent habituellement leurs produits sur les marchés d'agriculteurs ou directement au public. Ils présentent souvent leurs produits comme étant plus sains que les produits provenant de l'industrie commerciale, et ne voient donc pas toujours la nécessité de la biosécurité ou de la prévention des maladies. Ces producteurs ne sont peut-être pas aussi bien informés au sujet de la biosécurité ou des maladies, et mettent souvent en œuvre moins de mesures de biosécurité. Le grand public peut souvent être en contact direct avec les animaux vivants dans ces fermes. Étant donné que ce segment n'est pas représenté par une organisation de l'industrie, il peut être plus difficile à atteindre et à informer.

approches pour évaluer les résultats immunologiques. Selon certains auteurs, une personne infectée par une souche grippale d'origine animale produirait des titres d'anticorps faibles qui retourneraient, en peu de temps, aux taux préalables à l'infection. Dans ces cas, des seuils de coupure moins élevés sont utilisés pour déterminer la séropositivité ( $p$. ex. des titres $\geq 1: 10$ ou $\geq 1: 20$ ). D'autres études, cependant, ont utilisé des protocoles d'essai comme ligne directrice ainsi que des seuils plus élevés (p. ex. titres $\geq 1: 80$ ou $\geq 1: 160$ ), ce qui peut amener à sous-estimer la fréquence de l'infection hétérospécifique.

Le type de test utilisé pour les réponses de titres $d$ 'anticorps influence également les résultats. D'après certaines études, les tests de microneutralisation sont privilégiés pour évaluer la séroréaction, car ils sont très sensibles et précis. La quasi-totalité des études ont utilisé le test d'inhibition de l'hémagglutination $(\mathrm{IH})^{35}$, mais elles changeaient l'espèce d'érythrocytes utilisée. Le test d'IH dépend de la souche et, si l'appariement entre le test et les souches types est inadéquat, le test est limité dans sa capacité de détecter une réponse immunitaire chez une personne autrement infectée et en mesure de produire une réponse. 
La réactivité croisée entre les virus de la grippe porcine, aviaire et humaine est un autre facteur de confusion repris par une seule étude, ce qui a augmenté faussement les résultats positifs. II peut être difficile de déceler les réactions croisées potentielles, d'où une capacité limitée de distinguer leurs effets sur le résultat. La réactivité croisée peut être plus importante dans les études liées au virus de la grippe porcine. Même si le nombre d'études était limité, la séroréaction au virus de la grippe porcine semblait plus répandue que la séroréaction au virus de la grippe aviaire. Selon une étude, l'âge peut être un facteur, car les personnes plus âgées peuvent acquérir une immunité contre des souches de grippe qui ont probablement resurgi après une période dormante ${ }^{36}$. Une autre étude mentionnait le rôle de la vaccination antigrippale comme cause de réactions croisées lors des dépistages.

La discussion avec les membres du Groupe de travail sur la grippe aviaire et les vétérinaires en chef indique que diverses associations professionnelles ont des recommandations sur la vaccination saisonnière et que la majorité des vétérinaires en sont au courant. Le taux de vaccination, cependant, demeure inconnu. Au Canada, des mesures de biosécurité rigoureuses sont les moyens principaux de prévention de l'infection par le virus de la grippe aviaire et porcine.

\section{Recommandations/Justification}

Le contact direct avec la volaille infectée ou la contamination des surfaces et des objets par ses excréments est considéré à l'heure actuelle comme la principale voie d'infection des ouvriers par la grippe aviaire. Puisque les préposés à l'abattage se trouvent dans un environnement où il y a une grande concentration de volaille infectée ainsi que de surfaces et d'objets contaminés, le contexte est opportun pour la transmission virale. La volaille infectée peut déverser de grandes quantités de virus dans ses excréments et sécrétions respiratoires, et le processus d'abattage peut donner lieu à une exposition à ces sécrétions plus élevée que la normale. La grippe est endémique à la population porcine et les infections sont souvent bénignes ou asymptomatiques. Les ouvriers des porcheries et des poulaillers ne sont pas susceptibles de connaître la même intensité d'exposition aux virions que les préposés à l'abattage. En effet, on a relevé lors de l'examen de la documentation que les préposés à l'abattage avicole avaient plus souvent des résultats de sérologie positifs contre la grippe aviaire que d'autres ouvriers avicoles. Pour cette raison, les recommandations visant les ouvriers avicoles travaillant dans les activités d'abattage diffèrent de celles formulées pour les ouvriers des poulaillers et des porcheries.

\section{VI.1 OUVRIERS AVICOLES}

Le CCNI continue de recommander l'immunisation contre la grippe saisonnière chez les personnes en contact direct, durant les activités d'abattage, avec de la volaille infectée par le virus de la grippe aviaire (recommandation du CCNI de catégorie l); cependant, le CCNI encourage l'administration du vaccin antigrippal chez tous les Canadiens âgés de 6 mois et plus.

En se basant sur l'examen de la documentation et la discussion avec les spécialistes de la santé animale, le $\mathrm{CCNI}$ a conclu qu'il n'existe aucune preuve directe indiquant l'efficacité de la vaccination des ouvriers avicoles pour prévenir le réassortiment des souches aviaires ou humaines saisonnières chez les humains qui mènent à l'émergence des virus pandémiques. Cependant, la documentation fait état de la transmission de la grippe aviaire aux humains qui manipulent de la volaille comme source alimentaire. Le contact est habituellement étroit et soutenu avec l'animal (p. ex. abattage), et le risque de transmission est relativement faible. Dans un petit nombre d'études évaluant les ouvriers avicoles et les préposés à l'abattage, ces derniers formaient la majorité des cas séropositifs. On peut présumer que le contact entre un ouvrier travaillant dans l'abattage de la volaille infectée par le virus de la grippe aviaire serait plus long et important que tout autre type de contact avec la volaille. 
Selon des données probantes, les virus aviaires et humains peuvent se réassortir, et ce réassortiment peut avoir lieu chez les humains. La grippe ne circule pas habituellement dans les poulaillers commerciaux au Canada et, selon les spécialistes de la santé animale consultés par le CCNI, toutes les souches aviaires hautement pathogènes ainsi que les souches aviaires de $\mathrm{H} 5$ et de $\mathrm{H} 7$ sont à déclaration obligatoire au Canada. Bon nombre de pays font une recommandation similaire. D'après ce qui est connu des virus de la grippe et du réassortiment, le CCNI est d'avis que l'immunisation des ouvriers avicoles contre la grippe saisonnière peut prévenir un réassortiment chez les humains entre la souche aviaire lors d'une éclosion et les souches de grippe saisonnière chez les humains. Toutefois, étant donné l'efficacité variable du vaccin de la grippe saisonnière chez les adultes en santé et chez les adultes aux prises avec des problèmes de santé chroniques, la période de deux semaines entre l'immunisation et l'acquisition de l'immunité et l'avantage théorique, soit l'immunisation contre la grippe saisonnière en vue de prévenir le réassortiment des souches virales, devraient être utilisés comme mesure complémentaire aux autres mesures de biosécurité décrites ailleurs (p. ex. les antiviraux et l'équipement de protection individuelle $)^{37}$. De plus, on ne doit pas s'attendre à ce que le vaccin antigrippal saisonnier soit efficace contre une souche aviaire de grippe, compte tenu de la différence antigénique importante entre les souches (p. ex. H7N3, H9N2).

\section{VI.2 OUVRIERS DES PORCHERIES}

Le CCNI conclut que les données probantes sont actuellement insuffisantes pour recommander précisément la vaccination antigrippale systématique aux ouvriers des porcheries (recommandation du CCNI de catégorie I); cependant, le CCNI encourage l'administration du vaccin antigrippal chez tous les Canadiens âgés de 6 mois et plus.

En s'appuyant sur l'examen de la documentation et la discussion avec les spécialistes de la santé animale, le CCNI conclut qu'il n'existe aucune donnée probante selon laquelle la vaccination de ces ouvriers préviendrait l'émergence des souches pandémiques. En outre, il ne serait pas possible d'étudier cette question. Toutefois, $d^{\prime}$ 'après ce qui est connu de la transmission et du réassortiment des souches d'origine porcine et humaine, cela présenterait un avantage d'un point de vue théorique.
Nonobstant cette déclaration, le CCNI continue d'encourager l'administration du vaccin antigrippal à tous les Canadiens âgés de six mois et plus afin d'offrir une protection aux personnes qui souhaitent recevoir ce vaccin.

La prescription de recommandations concernant la vaccination des ouvriers des porcheries à des fins de protection des troupeaux de porcs ne fait pas partie de la mission du CCNI. Pour ce qui est de préoccupations concernant la santé animale, le lecteur aura intérêt à consulter les ressources pertinentes.

Les objectifs en matière d'immunisation des ouvriers de porcheries contre la grippe saisonnière peuvent varier:

- Protéger les troupeaux contre les souches humaines de la grippe.

- Protéger les ouvriers contre les souches porcines émergentes liées antigéniquement.

- Prévenir le réassortiment des souches porcines et humaines en souches pandémiques.

Le fardeau de la transmission entre les porcs et les ouvriers au Canada n'est pas bien connu. Contrairement aux éclosions de la grippe dans la volaille, les éclosions porcines de la grippe ne sont pas à déclaration obligatoire au Canada. Une étude menée en Alberta dans un nombre limité d'exploitations agricoles commerciales a permis de conclure que le risque de transmission des porcs aux ouvriers et vice versa était faible ${ }^{38}$. D'après les spécialistes des animaux consultés par le CCNI, les activités agricoles au Canada concernant les porcs appliquent habituellement plusieurs mesures de biosécurité. Cependant, la protection attribuable au vaccin humain comparativement à d'autres mesures de biosécurité est inconnue. De plus, comparativement à d'autres pays, l'occasion d'un contact direct entre les porcs vivants et le grand public est limitée au Canada. Cependant, tous les élevages n'appliquent pas des mesures de biosécurité de la même manière et, au Canada, certains ouvriers non protégés sont directement exposés aux porcs dans des endroits fermés. La transmission des variantes du virus porcin aux ouvriers des porcheries et à leurs contacts étroits a été recensée dans la documentation. Or, étant donné que de nombreuses infections par le virus de la grippe chez les humains et chez les porcs ne seraient pas signalées ou confirmées, il se peut que la transmission soit rarement recensée. En conclusion, le risque de transmission du virus de la grippe entre les humains et les porcs est relativement faible pour le grand public au Canada. Les ouvriers des porcheries des élevages commerciaux et artisanaux courent un plus grand risque que le grand public. 
Peu de pays ont mis en œuvre une recommandation pour la vaccination saisonnière des ouvriers des porcheries. Durant la saison contre la grippe de 2006-2007, le Royaume-Uni a mis en place un programme annuel de la grippe saisonnière pour les ouvriers avicoles, mais il a cessé après la saison de 2010-2011 en raison de questions logistiques, de faibles taux de vaccination et du fait que les ouvriers avicoles sont considérés comme un groupe de faible priorité. Au Canada, les recommandations varient : certaines provinces recommandent l'immunisation des ouvriers de porcheries; une province s'est prononcée contre l'immunisation, une autre a préconisé son adoption puis a retiré sa recommandation après des études menées en 2009 indiquant une association entre la réception de la vaccination saisonnière et l'infection par la souche pandémique $\mathrm{H} 1 \mathrm{~N} 1^{39}$. Certaines études affichent des résultats similaires chez les furets et les porcs après la vaccination saisonnière et après qu'ils ont été éprouvés par la souche pandémique H1N1 200940,41. L'Agence canadienne d'inspection des aliments recommande l'immunisation des ouvriers de porcheries contre la grippe saisonnière. La raison de cette recommandation consiste, entre autres, à protéger les troupeaux contre l'infection par les souches humaines de la grippe. Néanmoins, cette recommandation excède la portée du CCNI.
Dans le contexte de l'émergence de la variante du virus porcin, l'efficacité de l'immunisation des ouvriers de porcheries contre la grippe dépendrait grandement de la similarité antigénique entre la souche émergente et la formulation du vaccin antigrippal saisonnier offert au cours de cette saison particulière.

Le CCNI conclut que l'émergence de la variante du virus porcin, la virulence de la maladie et pour les porcs et les humains ainsi que l'efficacité du vaccin chez les humains sont susceptibles de varier. Ces facteurs devraient être évalués au cas par cas, ce qui permettrait d'établir si le profil des risques-avantages favorise une recommandation pour l'immunisation.

Enfin, l'innocuité du vaccin antigrippal a été recensée chez les adultes; les événements indésirables importants sont assez rares, l'effet secondaire le plus commun étant une douleur bénigne au point d'injection quelques jours après une injection intramusculaire. Pour plus de précisions sur l'innocuité de ces vaccins, veuillez consulter la section sur l'innocuité de la déclaration relative à la grippe de 2013-2014. 


\section{Références}

(1) Yan S, Wu G. Evidence obtained from ANOVA to reason cross-species infection and cross-subtype mutation in neuraminidases of influenza A viruses. Transbound Emerg Dis 2010;57(4):254-261.

(2) Organisation mondiale de la Santé. Cumulative number of confirmed human cases of avian influenza $A(H 5 N 1)$ reported to $W H O, 2013$. Accès : www.who.int/influenza/human_animal_interface/ H5N1_cumulative_table_archives/en

(3) Agence canadienne d'inspection des aliments. Surveillance de l'influenza aviaire. Accès : www.inspection.gc.ca/animaux/animaux-terrestres/ maladies/surveillance-des-maladies/surveillancede-I-influenza-aviaire/fra/1329693810008/132969429 8513, 2013.

(4) Nelli RK, Kuchipudi SV, White GA, Perez BB, Dunham $\mathrm{SP}$, Chang KC. Comparative distribution of human and avian type sialic acid influenza receptors in the pig. BMC Vet Res 2010;6:4-6148-6-4.

(5) Van Poucke SG, Nicholls JM, Nauwynck HJ, Van Reeth K. Replication of avian, human and swine influenza viruses in porcine respiratory explants and association with sialic acid distribution. Virol J 2010;7:38-422X-7-38.

(6) United States Department of Agriculture: Animal and Plant Health Inspection Service. Swine Influenza Surveillance. Accès: www.aphis.usda.gov/animal_health/animal_dis_ spec/swine/siv_surveillance.shtml, 2013.

(7) Organisation mondiale de la Santé. Préparation et action en cas de grippe pandémique. 2009.

(8) Organisation mondiale de la Santé. Grippe aviaire: évaluation du risque de pandémie. 2005.

(9) Garten RJ, Davis CT, Russell CA, et coll. Antigenic and genetic characteristics of swine-origin 2009 A(H1N1) influenza viruses circulating in humans. Science 2009;325(5937):197-201.

(10) Agence canadienne des médicaments et des technologies de la santé (ACMTS). Influenza vaccination for prevention of cross-species infection: A review of the clinical evidence. 2012.
(11) Cai W, Schweiger B, Buchholz U, et coll. Protective measures and $\mathrm{H} 5 \mathrm{~N} 1$-seroprevalence among personnel tasked with bird collection during an outbreak of avian influenza A/H5N1 in wild birds, Ruegen, Allemagne, 2006. BMC Infectious Diseases 2009;9:170.

(12) Alizadeh E, Kheiri MT, Bashar R, Tabatabaeian M, Hosseini SM. Avian influenza (H9N2) among poultry workers in Iran. Iranian Journal of Microbiology 2009;1(3):3-6. 3 réf. 2009.

(13) Arzey GG, Kirkland PD, Arzey KE, et coll. Influenza virus a (H10N7) in chickens and poultry abattoir workers, Australie. Emerging Infectious Diseases 2012;18(5):814-816.

(14) Bridges CB, Lim W, Hu-Primmer J, et coll. Risk of influenza $A$ (H5N1) infection among poultry workers, Hong Kong, 1997-1998. J Infect Dis 2002;185(8):1005-1010.

(15) Kwon D, Lee J-Y, Choi W, et coll. Avian influenza A (H5N1) virus antibodies in poultry cullers, Corée du Sud, 2003-2004. Emerging Infectious Diseases 2012;18(6):986-988.

(16) Ortiz JR, Katz MA, Mahmoud MN, et coll. Lack of evidence of avian-to-human transmission of avian influenza $A(H 5 N 1)$ virus among poultry workers, Kano, Nigeria, 2006. J Infect Dis 2007;196(11):1685-1691.

(17) Schultsz C, Nguyen VD, Hai le T, et coll. Prevalence of antibodies against avian influenza $A$ (H5N1) virus among cullers and poultry workers in Ho Chi Minh City, 2005. PLoS ONE 2009;4(11):e7948.

(18) Gray GC, Ferguson DD, Lowther PE, Heil GL, Friary JA. A national study of US bird banders for evidence of avian influenza virus infections. Journal of Clinical Virology 2011;51(2):132-135.

(19) Shafir SC, Fuller T, Smith TB, Rimoin AW. A national study of individuals who handle migratory birds for evidence of avian and swine-origin influenza virus infections. J Clin Virol 2012;54(4):364-367. 
(20) Vong S, Coghlan B, Mardy S, et coll. Low frequency of poultry-to-human $\mathrm{H} 5 \mathrm{NI}$ virus transmission, Cambodge du Sud, 2005. Emerging Infectious Diseases 2006;12(10):1542-1547.

(21) Ceyhan M, Yildirim I, Ferraris O, et coll. Serosurveillance study on transmission of $\mathrm{H} 5 \mathrm{~N} 1$ virus during a 2006 avian influenza epidemic. Epidemiology \& Infection 2010;138(9):1274-1280.

(22) Du Ry van Beest Holle M, Meijer A, Koopmans M, de Jager CM. Human-to-human transmission of avian influenza A/H7N7, les Pays-Bas, 2003. Euro surveillance : bulletin européen sur les maladies transmissibles = European communicable disease bulletin 2005;10(12):264-268.

(23) Gray GC, McCarthy T, Capuano AW, Setterquist SF, Alavanja MC, Lynch CF. Evidence for avian influenza A infections among iowa's agricultural workers. Influenza and other Respiratory Viruses 2008;2(2):61-69.

(24) Koopmans M, Wilbrink B, Conyn M, et coll. Transmission of H7N7 avian influenza A virus to human beings during a large outbreak in commercial poultry farms in the Netherlands. Lancet 2004;363(9409):587-593.

(25) Gray GC, Trampel DW, Roth JA. Pandemic influenza planning: Shouldn't swine and poultry workers be included? Vaccine 2007;25(22):4376-4381.

(26) Gerloff NA, Kremer JR, Charpentier E, et coll. Swine influenza virus antibodies in humans, Europe de I'Ouest, 2009. Emerging Infectious Diseases 2011;17(3):403-411.

(27) Robinson JL, Lee BE, Patel J, et coll. Swine influenza (H3N2) infection in a child and possible community transmission, Canada. Emerging Infectious Diseases 2007;13(12):1865-1870.

(28) Centers for Disease Control and Prevention (CDC). Morbidity and mortality weekly report-prevention and control of influenza with vaccines:

Recommendations of the advisory committee on immunization practices (ACIP), 2010. 6 août 2010 / 59(rr08);1-62.
(29) Centers for Disease Control and Prevention (CDC). Morbidity and mortality weekly report-prevention and control of influenza with vaccines: Recommendations of the advisory committee on immunization practices (ACIP)—United States, 2012-13 influenza season. 2012;61(32);613-618.

(30) Centers for Disease Control and Prevention (CDC). CDC interim guidance for workers who are employed at commercial swine farms: Preventing the spread of influenza A viruses, 2011.

(31) Mereckiene J, Cotter S, D'Ancona F, et coll. Differences in national influenza vaccination policies across the European Union, Norway and Iceland 2008-2009. Euro surveillance 2010;15(44).

(32) NACl Influenza Working Group. Record of decisions 17 décembre 2012.

(33) NACl Influenza Working Group. Anonymous.

(34) Global Influenza P. Expert consultation on diagnosis of H5N1 avian influenza infections in humans. Influenza \& Other Respiratory Viruses 2007;1(4):131-138.

(35) Rowe T, Abernathy RA, Hu-Primmer J, et coll. Detection of antibody to avian influenza A (H5N1) virus in human serum by using a combination of serologic assays. J Clin Microbiol 1999;37(4):937-943.

(36) Beaudoin A, Gramer M, Gray GC, Capuano A, Setterquist $S$, Bender J. Serologic survey of swine workers for exposure to H2N3 swine influenza A. Influenza and other Respiratory Viruses 2010;4(3):163-170.

(37) Agence canadienne d'inspection des aliments. Biosécurité animale. Accès : www.inspection.gc.ca/ animaux/animaux-terrestres/biosecurite/fra/12998680 55616/1320534707863, 2013-02-05.

(38) J. Keenliside. NACI IWG. Communication regarding unpublished Canadian swine influenza study, 29 avril, 2013.

(39) Skowronski DM, de Serres G, Crowcroft NS, et coll. Association between the 2008-09 seasonal influenza vaccine and pandemic H1N1 illness during springsummer 2009: Four observational studies from Canada. PLoS Medicine 2010;7(4). 
(40) Ellebedy AH, Ducatez MF, Duan S, et coll. Impact of prior seasonal influenza vaccination and infection on pandemic A (H1N1) influenza virus replication in ferrets. Vaccine 2011;29(17):3335-3339.

(41) Zhu H, Wang J, Zheng Z, et coll. Pathogenicity and transmissibility of the pandemic H1N1 2009-related influenza viruses in mice, ferrets, and pigs. Influenza \& Other Respiratory Viruses 2011;5(Supp| 1):82-84.

(42) Dejpichai R, Laosiritaworn Y, Phuthavathana P, et coll. Seroprevalence of antibodies to avian influenza virus A (H5N1) among residents of villages with human cases, Thaïlande, 2005. Emerging Infectious Diseases 2009; 15(5):756-760.

(43) Gray GC, McCarthy T, Capuano AW, Setterquist SF, Alavanja MC, Lynch CF. Evidence for avian influenza $A$ infections among lowa's agricultural workers. Influenza \& Other Respiratory Viruses 2008;2(2):61-69.

(44) Hinjoy S, Puthavathana P, Laosiritaworn Y, et coll. Low frequency of infection with avian influenza virus (H5N1) among poultry farmers, Thaïlande, 2004. Emerg Infect Dis 2008;14(3):499-501.

(45) Holle, M. R. D. R. van B., Setiawaty V, Pangesti KNA, Sedyaningsih ER. Seroprevalence of avian influenza A/H5N1 among poultry farmers in rural Indonesia, 2007. Southeast Asian Journal of Tropical Medicine and Public Health 2010;41(5):1095-1103. 14 réf. 2010.

(46) Huo X, Zu R, Qi X, et coll. Seroprevalence of avian influenza $A(H 5 N 1)$ virus among poultry workers in Jiangsu province, China: An observational study. BMC Infectious Diseases 2012;12.

(47) Jia N, de Vlas SJ, Liu YX, et coll. Serological reports of human infections of $\mathrm{H} 7$ and $\mathrm{H} 9$ avian influenza viruses in Northern China. Journal of Clinical Virology 2009;44(3):225-229.

(48) Kayali G, Ortiz EJ, Chorazy ML, Gray GC. Evidence of previous avian influenza infection among US turkey workers. Zoonoses and public health 2010;57(4):265-272.

(49) Kayali. Evidence of infection with $\mathrm{H} 4$ and $\mathrm{H} 11$ avian influenza viruses among Lebanese chicken growers. PLOS ONE 2011;6(10):e26818.

(50) Khuntirat BP, Yoon InKyu, Blair PJ, et coll. Evidence for subclinical avian influenza virus infections among rural Thai villagers. Clinical Infectious Diseases. 2011.
(51) Koopmans M, Wilbrink B, Conyn M, et coll. Transmission of H7N7 avian influenza A virus to human beings during a large outbreak in commercial poultry farms in the Netherlands. Lancet 2004;363(9409):587-593.

(52) Leibler JH, Silbergeld EK, Pekosz A, Gray GC. No evidence of infection with avian influenza viruses among US poultry workers in the Delmarva Peninsula, Maryland et Virginie, USA. J Agromed 2011;16(1):52-57.

(53) Lu CiYong, Lu JiaHai, Chen WeiQing, et coll. Potential infections of H5N1 and H9N2 avian influenza do exist in Guangdong populations of China. Chin Med J 2008(Beijing):121(20):2050-2053. 18 réf.

(54) Ogata T, Yamazaki Y, Okabe N, et coll. Human H5N2 avian influenza infection in Japan and the factors associated with high H5N2-neutralizing antibody titer. Journal of Epidemiology 2008;18(4):160-166. 20 réf. 2008.

(55) Ortiz EJ, Kochel TJ, Capuano AW, Setterquist SF, Gray GC. Avian influenza and poultry workers, Peru, 2006. Influenza and other respiratory viruses 2007;1(2):65-69.

(56) Ortiz JR, Katz MA, Mahmoud MN, et coll. Lack of evidence of avian-to-human transmission of avian influenza A (H5N1) virus among poultry workers, Kano, Nigeria, 2006. J Infect Dis 2007;196(11):1685-1691.

(57) Pawar SD, Tandale BV, Raut CG, et coll. Avian influenza H9N2 seroprevalence among poultry workers in Pune, India, 2010. PLoS ONE 2012;7(5), 18 mai 2012

(58) Puzelli S, Di Trani L, Fabiani C, et coll. Serological analysis of serum samples from humans exposed to avian $\mathrm{H} 7$ influenza viruses in italy between 1999 and 2003. J Infect Dis 2005;192(8):1318-1322.

(59) Santhia K, Ramy A, Jayaningsih P, et coll. Avian influenza A H5N1 infections in Bali province, Indonesia: A behavioral, virological and seroepidemiological study. Influenza and other respiratory viruses 2009;3(3):81-89.

(60) Wang M, Fu CX, Zheng BJ. Antibodies against H5 and $\mathrm{H} 9$ avian influenza among poultry workers in China. N Engl J Med 2009;360(24):2583-2584. 
(61) Yamazaki Y, Doy M, Okabe N, et coll. Serological survey of avian H5N2-subtype influenza virus infections in human populations. Arch Virol 2009;154(3):421-427.

(62) Ayora-Talavera G, Cadavieco-Burgos JM, CanulArmas AB. Serologic evidence of human and swine influenza in Mayan persons. Emerging Infectious Diseases 2005;11(1):158-161.

(63) Gray GC, McCarthy T, Capuano AW, et coll. Swine workers and swine influenza virus infections. Emerging Infectious Diseases 2007;13(12):1871-1878.

(64) Kitikoon P, Sreta D, Tuanudom R, et coll. Serological evidence of pig-to-human influenza virus transmission on Thai swine farms. Vet Microbiol 2011;148(2-4):413418. Date of Publication: 24 mars 2011.

(65) Krumbholz A, Lange J, Durrwald R, et coll. Prevalence of antibodies to swine influenza viruses in humans with occupational exposure to pigs, Thuringe, Allemagne, 2008-2009. J Med Virol 2010;82(9):1617-1625.

(66) Lopez-Robles G, Montalvo-Corral M, Caire-Juvera G, Ayora-Talavera G, Hernandez J. Seroprevalence and risk factors for swine influenza zoonotic transmission in swine workers from northwestern Mexico. Transbound Emerg Dis 2012;59(2):183-188.

(67) Myers KP, Olsen CW, Setterquist SF, et coll. Are swine workers in the United States at increased risk of infection with zoonotic influenza virus. Clinical Infectious Diseases 2006;42(1):14-20.
(68) Olsen CW, Brammer L, Easterday BC, et coll. Serologic evidence of $\mathrm{H} 1$ swine influenza virus infection in swine farm residents and employees. Emerging Infectious Diseases 2002;8(8):814-819. 37 réf. 2002.

(69) Olsen CW, Karasin Al, Carman S, et coll. Triple reassortant H3N2 influenza A viruses, Canada, 2005. Emerging Infectious Diseases 2006;12(7):1132-1135.

(70) Ramirez A, Capuano AW, Wellman DA, Lesher KA, Setterquist SF, Gray GC. Preventing zoonotic influenza virus infection. Emerging infectious diseases 2006;12(6):996-1000.

(71) Robinson JL, Lee BE, Patel J, et coll. Swine influenza (H3N2) infection in a child and possible community transmission, Canada. Emerging Infectious Diseases 2007;13(12):1865-1870.

(72) Terebuh P, Olsen CW, Wright J, et coll. Transmission of influenza A viruses between pigs and people, lowa, 2002-2004. Influenza and other Respiratory Viruses 2010;4(6):387-396.

(73) Harris RP, Helfand M, Woolf SH, et coll. Current methods of the US preventive services task force: A review of the process. Am J Prev Med 2001;20(3 Suppl):21-35. 


\section{Annexe A : Résumé des données probantes pour la recommandation du CCNI}

\begin{tabular}{|c|c|c|c|c|c|c|}
\hline \multicolumn{7}{|c|}{ PERSONNES AVEC UNE EXPOSITION PROFESSIONNELLE AUX POPULATIONS AVICOLES } \\
\hline Étude & $\begin{array}{l}\text { Modèle } \\
\text { d'étude }\end{array}$ & Participants & Type de grippe & Principales conclusions & Niveau & Qualité \\
\hline Alizadeh E. (2009) $)^{12}$ & $\begin{array}{l}\text { Séroprévalence } \\
\text { transversale }\end{array}$ & $\begin{array}{l}\mathrm{N}=152 \\
\mathrm{n}_{\text {exposé }}=127 \\
\mathrm{n}_{\text {témoin }}=25 \\
\text { Ouvriers avicoles et } \\
\text { d'abattoirs (tous des } \\
\text { hommes); témoins } \\
\text { avec une exposition } \\
\text { régulière à la volaille } \\
\text { liée à la consomma- } \\
\text { tion (60\% des } \\
\text { femmes) } \\
\text { Iran, nov. } 2006\end{array}$ & $\begin{array}{l}\text { Aviaire } \\
\text { H9N2 } \\
\text { H7N7 }\end{array}$ & $\begin{array}{l}\text { Test IH (protocole de l'OMS), ajusté } \\
\text { pour une réactivité croisée } \\
\text { potentielle entre le H3 et le H9 } \\
48 \text { ouvriers ( } 37,7 \% \text { ) étaient } \\
\text { séropositifs (titres } \geq 1: 20 \text { ) } \\
\text { La séropositivité chez les ouvriers } \\
\text { d'abattoirs était } 2,09 \text { fois plus } \\
\text { élevée que chez les ouvriers } \\
\text { avicoles ( } 51,6 \% \text { contre } 24,6 \% \text { ) } \\
83,3 \% \text { (20 sur } 24 \text { ) des ouvriers de } \\
\text { l'éviscération étaient séropositifs } \\
\text { H7N7 non détecté }\end{array}$ & III & Bonne \\
\hline Arzey G.G. $(2012)^{13}$ & $\begin{array}{l}\text { Dépistage } \\
\text { sérologique, } \\
\text { transversal }\end{array}$ & $\begin{array}{l}\mathrm{n}=7 \\
\text { Ouvriers d'abattoirs } \\
\text { symptomatiques } \\
\text { d'une entreprise } \\
\text { avicole commerciale } \\
\text { intensive dotée } \\
\text { d'une biosécurité } \\
\text { rigoureuse aux prises } \\
\text { avec une éclosion de } \\
\text { la grippe aviaire A } \\
\text { faiblement } \\
\text { pathogénique } \\
\text { Australie, mars } 2010\end{array}$ & $\begin{array}{l}\text { Aviaire } \\
\mathrm{H} 10 \mathrm{~N} 7\end{array}$ & $\begin{array}{l}\text { Test IH, Test MN } \\
\text { Les ouvriers ont affiché des signes } \\
\text { de conjonctivite, dont deux cas } \\
\text { signalant une rhinorrhée et un cas, } \\
\text { un mal de gorge } \\
\text { Des spécimens conjonctivaux ont } \\
\text { été prélevés par écouvillonnage } \\
\text { auprès de six ouvriers, des } \\
\text { échantillons du nez et de gorge ont } \\
\text { été prélevés par écouvillonnage } \\
\text { auprès de tous les ouvriers } \\
\text { Une analyse partielle des séquences } \\
\text { des échantillons de deux ouvriers a } \\
\text { confirmé la présence du sous-type } \\
\text { H10 de la grippe A (semblable au } \\
\text { sous-type H10 dans un isolat de } \\
\text { poulet), mais aucun virus cultivé } \\
\text { chez les ouvriers } \\
\text { L'équipement de protection } \\
\text { individuelle (EPI) n'était pas } \\
\text { fréquemment utilisé durant } \\
\text { l'éclosion }\end{array}$ & III & $\begin{array}{l}\text { Bonne } \\
\text { H10 confirmé } \\
\text { dans les } \\
\text { troupeaux de } \\
\text { volaille }\end{array}$ \\
\hline
\end{tabular}




\begin{tabular}{|c|c|c|c|c|c|c|}
\hline \multicolumn{7}{|c|}{ PERSONNES AVEC UNE EXPOSITION PROFESSIONNELLE AUX POPULATIONS AVICOLES } \\
\hline Étude & $\begin{array}{l}\text { Modèle } \\
\text { d'étude }\end{array}$ & Participants & Type de grippe & Principales conclusions & Niveau & Qualité \\
\hline $\begin{array}{l}\text { Bridges C.B. } \\
(2002)^{14}\end{array}$ & $\begin{array}{l}\text { Dépistage } \\
\text { sérologique avec } \\
\text { une analyse de } \\
\text { cas-témoins } \\
\text { emboîtés }\end{array}$ & $\begin{array}{l}\mathrm{N}=1818 \\
\mathrm{n}_{\text {ouvrier }}=1525 \\
\mathrm{n}_{\text {gouv. }}=293 \\
\text { Ouvriers avicoles } \\
\text { et employés du } \\
\text { gouvernement } \\
\text { travaillant dans } \\
\text { l'abattage avicole } \\
\text { Hong Kong, } \\
\text { 1997-1998 }\end{array}$ & $\begin{array}{l}\text { Aviaire } \\
\text { A/Duck/ } \\
\text { Singapore/-Q/ } \\
\text { F119-3/97 (H5N3) }\end{array}$ & $\begin{array}{l}\text { Test MN avec le test de } \\
\text { confirmation Western Blot; } \\
\text { Séropositif si les titres } \geq 80 \\
10 \% \text { ( } n=81 \text { ) des ouvriers avicoles } \\
\text { étaient séropositifs pour le H5 avec } \\
\text { les deux tests; } 29,1 \% \text { ( } n=444 \text { ) des } \\
\text { ouvriers avicoles étaient séropositifs } \\
\text { par MN uniquement } \\
\text { Les facteurs associés statistique- } \\
\text { ment à la séropositivité pour le H5 } \\
\text { étaient le signalement de décès } \\
>10 \% \text { dans la volaille et le } \\
\text { dépeçage de la volaille } \\
3 \text { \% ( } n=9 \text { ) des employés du } \\
\text { gouvernement étaient séropositifs } \\
\text { pour le H5 dans les deux essais; } \\
229 \text { ouvriers ont fourni plus d'un } \\
\text { échantillon de sérum et un ouvrier a } \\
\text { subi une séroconversion } \\
\text { Le fait d'être fumeur était } \\
\text { statistiquement associé au fait } \\
\text { d'être séropositif pour le H5 } \\
\text { ( } p=0,03 \text { ) chez les employés du } \\
\text { gouvernement, mais pas chez les } \\
\text { ouvriers avicoles }\end{array}$ & $\|-2$ & $\begin{array}{l}\text { Passable } \\
\text { Seul } 1 \text { échantillon } \\
\text { a été prélevé } \\
\text { auprès des } \\
\text { ouvriers avicoles; } \\
\text { il n'est donc pas } \\
\text { certain que la } \\
\text { séropositivité soit } \\
\text { le résultat d'une } \\
\text { exposition } \\
\text { actuelle ou } \\
\text { précédente }\end{array}$ \\
\hline Cai W. (2009) $)^{11}$ & $\begin{array}{l}\text { Enquête } \\
\text { transversale avec } \\
\text { dépistage } \\
\text { sérologique }\end{array}$ & $\begin{array}{l}\mathrm{N}=97 \\
\text { Pompiers, employés } \\
\text { du gouvernement et } \\
\text { vétérinaires } \\
\text { participant à la } \\
\text { collecte d'oiseaux } \\
\text { sauvages durant une } \\
\text { éclosion du H5N1 } \\
\text { Allemagne, } \\
\text { févr.-mars 2006 } \\
\text { (données recueillies } \\
\text { en mars 2007) }\end{array}$ & $\begin{array}{l}\text { Humaine } \\
\text { A/Wisconsin/67/05 } \\
\text { (H3N2) } \\
\text { A/New } \\
\text { Caledonia/20/99 } \\
\text { (H1N1) } \\
\text { Aviaire } \\
\text { A/whooper swan/ } \\
\text { R65-2/ } \\
\text { Germany/2006 } \\
\text { (H5N1) } \\
\text { A/bar-headed } \\
\text { goose/ } \\
\text { Qinghai/1A/2005 } \\
\text { (H5N1) } \\
\text { A/whooper swan/ } \\
\text { Mongolia/244/2005 } \\
\text { (H5N1) }\end{array}$ & $\begin{array}{l}\text { Test MN, plaque de neutralisation - } \\
\text { réactif si les titres anti-H5 } \geq 1: 20 ; \\
\text { réactivité croisée au } \mathrm{H} 1 \mathrm{~N} 1 \text { et au } \\
\mathrm{H} 3 \mathrm{~N} 2 \text { évaluée } \\
97 \% \text { ont déclaré utiliser au moins un } \\
\text { EPI durant la collecte d'oiseaux } \\
7 \text { participants sur } 90 \text { (8 \%) ont } \\
\text { signalé des symptômes de maladie } \\
\text { respiratoire aiguë durant la période } \\
\text { de collecte d'oiseaux ou jusqu'à } \\
5 \text { jours après (toux, rhume, céphalée, } \\
\text { douleur musculaire ou des membres) } \\
78 \text { participants sur } 97 \text { (80 \%) ont fourni } \\
\text { des échantillons de sérum } \\
5 \text { échantillons réactifs contre le H5, } \\
\text { dont un échantillon affichant une } \\
\text { réplication virale réduite dès le test } \\
\text { initial (un nouveau test à l'OMS a } \\
\text { donné des résultats négatifs); tous les } \\
5 \text { échantillons provenaient de } \\
\text { pompiers et affichaient des titres } \\
\text { d'anticorps élevés contre le H1N1 }\end{array}$ & III & $\begin{array}{l}\text { Passable } \\
\text { Étude menée une } \\
\text { année après } \\
\text { l'éclosion; il peut } \\
\text { y avoir des } \\
\text { problèmes avec } \\
\text { le rappel pour les } \\
\text { questions } \\
\text { d'enquête et la } \\
\text { capacité de } \\
\text { détecter la } \\
\text { séroconversion } \\
\text { puisque le H5 } \\
\text { décline } \\
\text { rapidement } \\
\text { La participation } \\
\text { était plus faible } \\
\text { chez les pompiers } \\
\text { (55\%) compara- } \\
\text { tivement aux } \\
\text { autres partici- } \\
\text { pants (> } 80 \% \\
\text { pour les } \\
\text { employés du } \\
\text { gouvernement et } \\
\text { les vétérinaires) }\end{array}$ \\
\hline
\end{tabular}




\begin{tabular}{|c|c|c|c|c|c|c|}
\hline \multicolumn{7}{|c|}{ PERSONNES AVEC UNE EXPOSITION PROFESSIONNELLE AUX POPULATIONS AVICOLES } \\
\hline Étude & $\begin{array}{l}\text { Modèle } \\
\text { d'étude }\end{array}$ & Participants & Type de grippe & Principales conclusions & Niveau & Qualité \\
\hline Ceyhan M. $(2010)^{21}$ & $\begin{array}{l}\text { Enquête avec } \\
\text { dépistage } \\
\text { sérologique; } \\
\text { échantillon de } \\
\text { sérum jumelé et } \\
\text { prélevé pour les } \\
\text { travailleurs de la } \\
\text { santé seulement, } \\
\text { un échantillon } \\
\text { pour tous les } \\
\text { autres; échantil- } \\
\text { lons testés à l'insu }\end{array}$ & $\begin{array}{l}\mathrm{N}=381 \text { (478 } \\
\text { échantillons de } \\
\text { sérum) } \\
\mathrm{n}_{\text {cas }}=5 \\
\mathrm{n}_{\text {famille }}=28 \\
\mathrm{n}_{\text {préposé à'abattage }}=95 \\
\mathrm{n}_{\text {contact asympt. }}=75 \\
\mathrm{n}_{\text {aucun contact }}=81 \\
\text { Personnes atteintes } \\
\text { par l'éclosion : cas } \\
\text { survivants, membres } \\
\text { de la famille exposés } \\
\text { aux personnes } \\
\text { touchées durant la } \\
\text { phase contagieuse, } \\
\text { personnes travaillant } \\
\text { dans l'abattage, } \\
\text { personnes } \\
\text { asymptomatiques en } \\
\text { contact avec des } \\
\text { poulets malades } \\
\text { dans les régions où } \\
\text { surviennent les cas, } \\
\text { personnes sans } \\
\text { contact connu avec } \\
\text { les poulets malades, } \\
\text { travailleurs de la } \\
\text { santé asymptoma- } \\
\text { tiques en contact } \\
\text { avec les personnes } \\
\text { touchées } \\
\text { Turquie, févr. } 2006\end{array}$ & $\begin{array}{l}\text { Aviaire } \\
\text { A/Turkey/13/06 } \\
\text { (H5N1) } \\
\text { A/Turkey/ } \\
\text { Turkey/1/2005 } \\
\text { (H5N1) }\end{array}$ & $\begin{array}{l}\text { ELISA (positif si l'absorbance } \\
\geq 620 \mathrm{~nm} \text { ); test IH (positif si } \geq 20 \text { ); } \\
\text { test MN (positif si titre } \geq 10 \text { ) utilisé } \\
\text { avec des échantillons d'anticorps } \\
\text { provenant des tests ELISA ou d'IH, } \\
\text { et vérification d'un échantillon } \\
\text { aléatoire de tests IH négatifs } \\
\text { Seuls cas évoquant des symptômes } \\
\text { de grippe aviaire } \\
4 \text { échantillons positifs découverts } \\
\text { à l'aide d'un test MN ( } 3 \text { cas, } \\
1 \text { membre de la famille) }\end{array}$ & $\|-3$ & $\begin{array}{l}\text { Passable } \\
\text { Méthodes de } \\
\text { laboratoire non } \\
\text { standardisées }\end{array}$ \\
\hline $\begin{array}{l}\text { Dejpichai R. } \\
(2009)^{42}\end{array}$ & $\begin{array}{l}\text { Enquête } \\
\text { transversale } \\
\text { sur la } \\
\text { séroprévalence }\end{array}$ & $\begin{array}{l}\mathrm{N}=901 \\
\text { Les villages ruraux où } \\
\text { l'agriculture } \\
\text { artisanale est } \\
\text { courante, mais qui } \\
\text { n'ont pas de marchés } \\
\text { de volaille vivante } \\
\text { Thaïlande, oct. } 2005\end{array}$ & $\begin{array}{l}\text { Aviaire } \\
\text { A/Thailand/ } \\
1(\text { KAN-1)/ } \\
2004(\mathrm{H} 5 \mathrm{~N} 1)\end{array}$ & $\begin{array}{l}\text { Test MN (positif si les titres } \geq 40 \text { ) } \\
\text { confirmé à l'aide de l'épreuve de } \\
\text { confirmation par immunofluores- } \\
\text { cence } \\
68,1 \% \text { des participants ont déclaré } \\
\text { un contact direct ou étroit avec } \\
\text { l'élevage artisanal de la volaille } \\
110 \text { participants ont déclaré des } \\
\text { antécédents de maladie respiratoire } \\
\text { aiguë : } 74,5 \% \text { ont déclaré un } \\
\text { contact direct ou étroit avec } \\
\text { l'élevage artisanal de la volaille, } \\
31,8 \% \text { ont déclaré un contact direct } \\
\text { ou étroit avec de la volaille malade } \\
\text { ou morte, } 13,6 \% \text { ont déclaré un } \\
\text { contact direct ou étroit avec une } \\
\text { personne ayant une infection } \\
\text { confirmée par le virus H5N1 } \\
\text { Tous les participants étaient } \\
\text { séronégatifs pour les anticorps } \\
\text { neutralisants contre le H5N1 }\end{array}$ & III & $\begin{array}{l}\text { Passable } \\
\text { Potentiel pour un } \\
\text { biais de rappel } \\
\text { puisque l'enquête } \\
\text { a été menée au } \\
\text { cours d'une } \\
\text { éclosion survenue } \\
\text { en } 2004\end{array}$ \\
\hline
\end{tabular}


PERSONNES AVEC UNE EXPOSITION PROFESSIONNELLE AUX POPULATIONS AVICOLES

\begin{tabular}{|c|c|c|c|c|c|c|}
\hline Étude & $\begin{array}{l}\text { Modèle } \\
\text { d'étude }\end{array}$ & Participants & Type de grippe & Principales conclusions & Niveau & Qualité \\
\hline $\begin{array}{l}\text { Du Ry van Beest } \\
\text { Holle, M. (2005) }{ }^{22}\end{array}$ & $\begin{array}{l}\text { Enquête avec } \\
\text { dépistage } \\
\text { sérologique }\end{array}$ & $\begin{array}{l}\mathrm{N}=62 \text { (avec } 25 \text { cas } \\
\text { index A/H7N7) } \\
\text { Les membres du } \\
\text { ménage exposés à } \\
\text { des cas index A/ } \\
\text { H7N7 confirmés } \\
\text { (ouvriers avicoles } \\
\text { infectés); les } \\
\text { personnes vivant } \\
\text { dans des fermes } \\
\text { avicoles ou } \\
\text { artisanales étaient } \\
\text { exclues } \\
\text { Pays-Bas, } 2003\end{array}$ & $\begin{array}{l}\text { Aviaire } \\
\text { A/H7N7 }\end{array}$ & $\begin{array}{l}\text { Test IH (positif si les titres } \geq 1: 10 \text { ) au } \\
\text { moins } 3 \text { semaines après le } \\
\text { diagnostic du premier cas dans le } \\
\text { ménage, échantillon simple } \\
8 \text { personnes (12,9\%) ont déclaré } \\
\text { des plaintes liées à la santé } \\
\text { (2 répondaient à la définition de cas } \\
\text { pour la conjonctivite uniquement, } \\
4 \text { répondaient à la définition de cas } \\
\text { pour les symptômes grippaux } \\
\text { uniquement et } 2 \text { répondaient aux } \\
\text { deux définitions) } \\
56 \text { participants sur } 62 \text { ont fourni } \\
\text { des échantillons de sérum et } \\
33 \text { participants ( } 58,9 \% \text { avaient des } \\
\text { anticorps détectables contre le H7 } \\
\text { Des } 24 \text { ménages soumis à des tests } \\
\text { sérologiques, } 15 \text { (62,5\%) avaient au } \\
\text { moins un contact dans le ménage } \\
\text { avec des anticorps détectables } \\
\text { contre le H7 } \\
\text { Les anticorps d'IH contre le virus de } \\
\text { comporippe A/H7, A/H1 et A/H3 ne } \\
\text { dans le test MN }\end{array}$ & III & $\begin{array}{l}\text { Passable } \\
\text { Taux de } \\
\text { non-réponse } \\
\text { élevé ( } 26,4 \% \text { des } \\
\text { ménages) sans } \\
\text { aucune analyse } \\
\text { effectuée pour } \\
\text { comparer les } \\
\text { ménages } \\
\text { répondants et les } \\
\text { ménages non } \\
\text { répondants }\end{array}$ \\
\hline
\end{tabular}




\begin{tabular}{|c|c|c|c|c|c|c|}
\hline \multicolumn{7}{|c|}{ PERSONNES AVEC UNE EXPOSITION PROFESSIONNELLE AUX POPULATIONS AVICOLES } \\
\hline Étude & $\begin{array}{l}\text { Modèle } \\
\text { d'étude }\end{array}$ & Participants & Type de grippe & Principales conclusions & Niveau & Qualité \\
\hline Gray G.C. $(2008)^{43}$ & $\begin{array}{l}\text { Enquête } \\
\text { longitudinale } \\
\text { avec dépistage } \\
\text { sérologique } \\
\text { (au départ, } \\
12 \text { et } 24 \text { mois) }\end{array}$ & $\begin{array}{l}N=798 \\
n_{\text {exposé }}=372 \\
n_{\text {épouse non exposée }}=368 \\
n_{\text {témoin }}=66 \\
\text { Ouvriers agricoles } \\
\text { ruraux exposés à la } \\
\text { volaille; épouses non } \\
\text { exposées; témoins } \\
\text { universitaires } \\
\text { É.-U., 2004-2006 }\end{array}$ & $\begin{array}{l}\text { Humaine } \\
\text { A/New Caledonia/ } \\
\text { 20/99 (H1N1) } \\
\text { A/Nanchang/g/ } \\
\text { 933/95 (H3N2) } \\
\text { A/Panama/2007/ } \\
99 \text { (H3N2) } \\
\text { Aviaire } \\
\text { A/Duck/Cz/ } \\
\text { 1/56 (H4N6) } \\
\text { A/Chucker/MN/ } \\
\text { 14591-7/98 (H5N2) } \\
\text { A/Turkey/MA/ } \\
65 \text { (H6N2) } \\
\text { A/Turkey/NA/ } \\
\text { 4529/02 (H7N2) } \\
\text { A/Turkey/MN/ } \\
\text { 38391-6/95 (H9N2) }\end{array}$ & 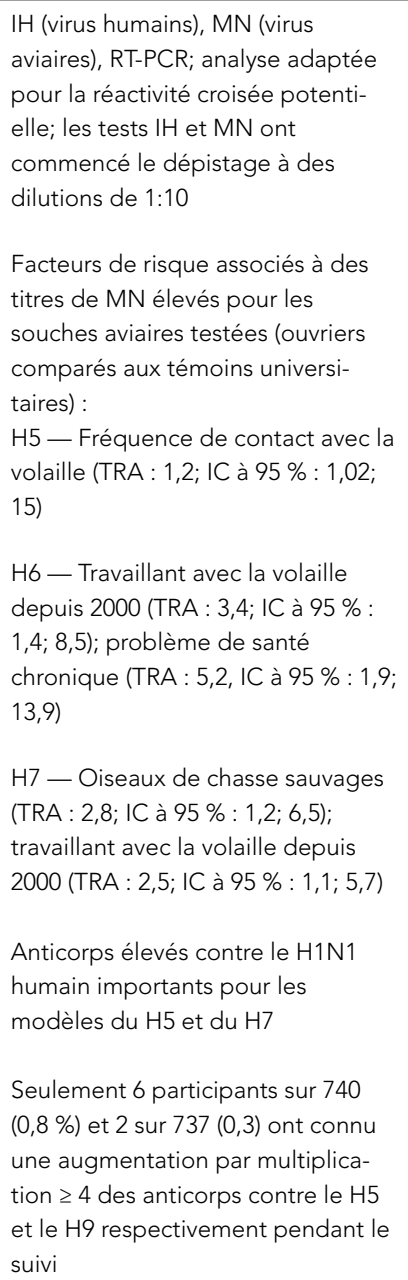 & $\|-2$ & $\begin{array}{l}\text { Médiocre } \\
\text { Groupe témoin } \\
\text { de participants } \\
\text { universitaires mal } \\
\text { appariés (plus } \\
\text { jeunes que les } \\
\text { personnes } \\
\text { exposées) } \\
\text { Des biais } \\
\text { potentiels } \\
\text { peuvent être } \\
\text { introduits par une } \\
\text { participation } \\
\text { volontaire, une } \\
\text { autodéclaration } \\
\text { de l'exposition, } \\
\text { un mauvais } \\
\text { appariement } \\
\text { potentiel entre } \\
\text { l'étude et les virus } \\
\text { circulant, des } \\
\text { anticorps à } \\
\text { réactivité croisée } \\
\text { non dénombrés }\end{array}$ \\
\hline Gray G.C. $(2011)^{18}$ & $\begin{array}{l}\text { Séroprévalence } \\
\text { transversale, } \\
\text { témoins appariés } \\
\text { selon le groupe } \\
\text { d'âge }\end{array}$ & $\begin{array}{l}N=235 \\
n_{\text {exposé }}=157 \\
n_{\text {témoin }}=78 \\
\text { Bagueurs d'oiseaux } \\
\text { enregistrés > } 18 \text { ans } \\
\text { et actifs au cours des } \\
12 \text { derniers mois; } \\
\text { témoins } \\
\text { universitaires } \\
\text { É.-U., 2009/2010 }\end{array}$ & $\begin{array}{l}\text { Humaine } \\
4 \text { souches } \\
\text { Aviaire } \\
8 \text { souches }\end{array}$ & $\begin{array}{l}\text { IH (échantillons humains; titres } \\
\text { élevés estimés à } \geq 1: 40 \text { ), MN } \\
\text { (échantillons aviaires; titres élevés } \\
\text { estimés à } \geq 1: 10 \text { ), RT-PCR } \\
\text { Échantillons de sérum prélevés } \\
\text { auprès de } 127 \text { ( } 81 \% \text { ) bagueurs } \\
\text { d'oiseaux et de } 69 \text { (88 \%) témoins } \\
3 \text { bagueurs d'oiseaux et } 1 \text { témoin } \\
\text { avaient un titre élevé contre le } \\
\text { H7N3, le H9N2 ou le H11N3 (virus } \\
\text { de grippe aviaire); Les bagueurs } \\
\text { d'oiseaux ont déclaré baguer des } \\
\text { oiseaux de proie sauvages } \\
15 \% \text { des bagueurs d'oiseaux ont } \\
\text { déclaré porter des gants, } 36 \% \text { ont } \\
\text { utilisé une protection des yeux et } \\
78 \% \text { ont fait un lavage des mains } \\
\text { souvent ou chaque fois }\end{array}$ & III & $\begin{array}{l}\text { Passable } \\
\text { Les groupes } \\
\text { n'étaient pas } \\
\text { entièrement } \\
\text { comparables; des } \\
\text { souches mal } \\
\text { appariées } \\
\text { pouvaient } \\
\text { produire des } \\
\text { résultats positifs } \\
\text { erronés }\end{array}$ \\
\hline
\end{tabular}




\begin{tabular}{|c|c|c|c|c|c|c|}
\hline \multicolumn{7}{|c|}{ PERSONNES AVEC UNE EXPOSITION PROFESSIONNELLE AUX POPULATIONS AVICOLES } \\
\hline Étude & $\begin{array}{l}\text { Modèle } \\
\text { d'étude }\end{array}$ & Participants & Type de grippe & Principales conclusions & Niveau & Qualité \\
\hline Hinjoy S. (2008) ${ }^{44}$ & $\begin{array}{l}\text { Enquête } \\
\text { transversale } \\
\text { sur la } \\
\text { séroprévalence }\end{array}$ & $\begin{array}{l}\mathrm{N}=322 \\
\text { Aviculteurs } \\
\text { Thaillande, } 2004\end{array}$ & $\begin{array}{l}\text { Aviaire } \\
\text { H5N1 }\end{array}$ & $\begin{array}{l}\text { MN (positif si } \geq 80 \text { à l'aide des tests } \\
\text { de confirmation ELISA ou Western } \\
\text { Blot) } \\
\text { Aucun participant n'a été découvert } \\
\text { positif d'après le seuil de coupure, } \\
\text { mais } 7 \text { ( } 2,2 \% \text { ) avaient des titres } \\
\text { d'anticorps réactifs faibles ( } 4 \text { avaient } \\
\text { des titres de } 10 ; 2 \text {, des titres de } 20 \\
\text { et } 1 \text {, des titres de } 40 \text { ) }\end{array}$ & III & $\begin{array}{l}\text { Passable } \\
\text { Participation } \\
\text { volontaire; pas } \\
\text { d'analyse } \\
\text { comparative } \\
\text { effectuée entre } \\
\text { les répondants et } \\
\text { les } \\
\text { non-répondants }\end{array}$ \\
\hline $\begin{array}{l}\text { Du Ry van Beest } \\
\text { Holle, M. (2010) }\end{array}$ & $\begin{array}{l}\text { Enquête } \\
\text { transversale sur la } \\
\text { séroprévalence } \\
\text { (échantillon } \\
\text { simple de sérum) }\end{array}$ & $\begin{array}{l}\mathrm{N}=495 \\
\text { Personnes travaillant } \\
\text { ou habitant dans } \\
12 \text { exploitations } \\
\text { agricoles provenant } \\
\text { d'une autre étude sur } \\
\text { l'efficacité des } \\
\text { vaccins } \\
\text { Indonésie, janv.-févr. } \\
2007\end{array}$ & $\begin{array}{l}\text { Aviaire } \\
\text { A/Ck/Banten/ } \\
\text { 05-1116/05 (H5N1) } \\
\text { A/H5N1/Indo/05/ } \\
\text { IBCDC-RG }\end{array}$ & $\begin{array}{l}\text { IH (positif : titre } \geq 160 \text { avec } 2 \text { tests } \\
\text { indépendants), MN (positif : titre } \\
\geq 80 \text { avec } 2 \text { tests indépendants) } \\
\text { Une exploitation agricole a connu } \\
\text { une éclosion, mais aucune preuve } \\
\text { d'anticorps contre le virus de la } \\
\text { grippe A/H5N1 n'a été détectée } \\
1 \text { personne avait un titre de } 20 \text { (test } \\
\text { IH), qui n'était pas concluant } \\
55 \text { (11 \%) personnes se sont plaintes } \\
\text { de la fièvre et de la toux au cours } \\
\text { des } 6 \text { derniers mois; } 17 \text { (3 \%) ont } \\
\text { signalé des symptômes grippaux, } \\
\text { dont un cas ayant été exposé à des } \\
\text { mortalités inhabituelles chez la } \\
\text { volaille à la ferme }\end{array}$ & III & $\begin{array}{l}\text { Passable } \\
\text { Participation } \\
\text { volontaire, pas } \\
\text { d'analyse } \\
\text { comparative } \\
\text { effectuée entre } \\
\text { les répondants et } \\
\text { les } \\
\text { non-répondants }\end{array}$ \\
\hline Huo X. $(2012)^{46}$ & $\begin{array}{l}\text { Enquête } \\
\text { transversale sur la } \\
\text { séroprévalence } \\
\text { (échantillon } \\
\text { simple de sérum) }\end{array}$ & $\begin{array}{l}\mathrm{N}=306 \\
\text { Ouvriers avicoles des } \\
\text { fermes avicoles } \\
\text { artisanales } \\
\text { Chine, juill.-août } \\
2010\end{array}$ & $\begin{array}{l}\text { Aviaire } \\
\text { A/Anhui/1/05 } \\
\text { A/Hubei/1/10 }\end{array}$ & $\begin{array}{l}\text { IH (globules rouges du cheval, } \\
\text { positif : titre } \geq 1: 160 \text { ) } \\
\text { Taux global de séropositivité pour le } \\
\text { H5N1: } 2,61 \% \text { (IC à } 95 \%: 1,14 ; 5,09 \text { ) } \\
\text { Les taux de séropositivité étaient en } \\
\text { grande corrélation avec les } \\
\text { médianes du nombre grandissant } \\
\text { de volailles par troupeau } \\
\text { Le nombre de volailles par troupeau } \\
\text { était associé à un risque accru de } \\
2,39 \text { (IC à } 95 \% \text { : 1,00; } 5,69 \text { ) pour les } \\
\text { ouvriers avicoles séropositifs ajustés } \\
\text { selon l'âge et le sexe }\end{array}$ & III & $\begin{array}{l}\text { Passable } \\
\text { Réactivité croisée } \\
\text { non prise en } \\
\text { compte }\end{array}$ \\
\hline
\end{tabular}




\begin{tabular}{|c|c|c|c|c|c|c|}
\hline \multicolumn{7}{|c|}{ PERSONNES AVEC UNE EXPOSITION PROFESSIONNELLE AUX POPULATIONS AVICOLES } \\
\hline Étude & $\begin{array}{l}\text { Modèle } \\
\text { d'étude }\end{array}$ & Participants & Type de grippe & Principales conclusions & Niveau & Qualité \\
\hline Jia N. (2009) $)^{47}$ & $\begin{array}{l}\text { Séroprévalence } \\
\text { transversale } \\
\text { (échantillon } \\
\text { simple de sérum) }\end{array}$ & $\begin{array}{l}\mathrm{N}=1467 \\
\text { Agriculteurs et } \\
\text { ouvriers avicoles } \\
\text { dans les villages } \\
\text { ruraux } \\
\text { Chine, avr. } 2006\end{array}$ & $\begin{array}{l}\text { Aviaire } \\
\text { A/African Starling/ } \\
\text { England-Q/938/ } \\
79 \text { (H7N1) } \\
\text { A/Chicken/ } \\
\text { Shanghai/ } \\
\text { 10/01 (H9N2) }\end{array}$ & $\begin{array}{l}\text { IH (globules rouges du cheval, } \\
\text { positif : titre } \geq 1: 160 \text { ) } \\
12 \text { échantillons étaient positifs pour } \\
\text { le H9, aucun ne l'était pour le H7 } \\
\text { Aucune association importante } \\
\text { entre la réaction au H9 et } \\
\text { l'exposition à la volaille morte ou } \\
\text { malade, mais trois quarts des sujets } \\
\text { avec des titres les plus élevés pour } \\
\text { le H9 (> 1:320) ont déclaré une } \\
\text { exposition à la volaille morte ou } \\
\text { malade chez eux }\end{array}$ & III & $\begin{array}{l}\text { Passable } \\
\text { Aucune norme } \\
\text { régissant le test } \\
\text { IH pour le H7 ou } \\
\text { le H9, donc le } \\
\text { critère de l'OMS } \\
\text { pour le H5N1 a } \\
\text { été utilisé; seul le } \\
\text { test IH a été } \\
\text { utilisé comme } \\
\text { moyen de } \\
\text { dépistage } \\
\text { sérologique; } \\
\text { réactivité croisée } \\
\text { non prise en } \\
\text { compte dans } \\
\text { l'analyse }\end{array}$ \\
\hline Kayali G. $(2010)^{48}$ & $\begin{array}{l}\text { Enquête } \\
\text { transversale sur la } \\
\text { séroprévalence } \\
\text { (échantillon } \\
\text { simple de sérum) }\end{array}$ & $\begin{array}{l}\mathrm{N}=177 \\
\mathrm{n}_{\text {producteur }}=57 \\
\mathrm{n}_{\text {ourrier }}=38 \\
\mathrm{n}_{\text {témoin }}=82 \\
\text { Producteurs de } \\
\text { dindon (artisanal et } \\
\text { en confinement), } \\
\text { ouvriers d'usine de } \\
\text { transformation de la } \\
\text { viande de dindon; } \\
\text { témoins non exposés } \\
\text { É.-U., mars } 2007 \text { - } \\
\text { avr. } 2008\end{array}$ & $\begin{array}{l}\text { Humaine } \\
\text { A/New Caledonia/ } \\
\text { 20/99 (H1N1) } \\
\text { A/Panama/2007/ } \\
99 \text { (H3N2) } \\
\text { Aviaire } \\
\text { H4N6 } \\
\text { H5N2 } \\
\text { H6N2 } \\
\text { H7N2 } \\
\text { H8N4 } \\
\text { H9N2 } \\
\text { H11N9 }\end{array}$ & $\begin{array}{l}\text { MN (positif à des dilutions } \geq 1: 10, \\
\text { test en double), IH (cochon d'Inde, } \\
\text { positif à } \geq 1: 40, \text { test pour la } \\
\text { réactivité croisée) } \\
14 \text { participants sur } 95 \text { (15\%) } \\
\text { exposés avaient des titres } \\
\text { d'anticorps élevés contre le virus de } \\
\text { la grippe aviaire comparativement à } \\
7 \text { témoins sur } 82 \text { (8,2 \%) } \\
\text { Les titres contre le H5 étaient plus } \\
\text { élevés pour les producteurs que } \\
\text { pour les témoins ( } p=0,003) \text {; ajustés } \\
\text { pour le H3N2 TRA : } 4,5 \text { (IC à } 95 \% \text { : } \\
\text { 1,5; } 13,3 \text { ) en cas de séropositivité } \\
\text { pour le H5 } \\
\text { Aucune différence dans les titres } \\
\text { pour le H7 et le H11 entre les } \\
\text { groupes, mais les producteurs } \\
\text { (notamment à petite échelle) } \\
\text { avaient des titres élevés pour tous } \\
\text { les autres sous-types testés } \\
\text { Les facteurs de risque potentiels } \\
\text { tels que l'âge, le sexe, le tabagisme, } \\
\text { les maladies chroniques, les } \\
\text { symptômes grippaux, l'utilisation } \\
\text { d'un équipement de protection } \\
\text { individuelle (EPI) n'étaient pas } \\
\text { associés aux résultats sérologiques }\end{array}$ & III & $\begin{array}{l}\text { Passable } \\
\text { Petits nombres; } \\
\text { usage de seuils } \\
\text { faibles pour les } \\
\text { essais; potentiel } \\
\text { de réactivité } \\
\text { croisée entre les } \\
\text { virus de grippe } \\
\text { aviaire }\end{array}$ \\
\hline
\end{tabular}




\begin{tabular}{|c|c|c|c|c|c|c|}
\hline \multicolumn{7}{|c|}{ PERSONNES AVEC UNE EXPOSITION PROFESSIONNELLE AUX POPULATIONS AVICOLES } \\
\hline Étude & $\begin{array}{l}\text { Modèle } \\
\text { d'étude }\end{array}$ & Participants & Type de grippe & Principales conclusions & Niveau & Qualité \\
\hline Kayali G. $(2011)^{49}$ & $\begin{array}{l}\text { Séroprévalence } \\
\text { transversale } \\
\text { (échantillon } \\
\text { simple de sérum) }\end{array}$ & $\begin{array}{l}\mathrm{N}=250 \\
\mathrm{n}_{\text {artisanal }}=128 \\
\mathrm{n}_{\text {commercial }}=72 \\
\mathrm{n}_{\text {témoin }}=50 \\
\text { Éleveurs de poulets } \\
\text { (artisanaux et } \\
\text { commerciaux); } \\
\text { témoins urbains (non } \\
\text { exposés à la volaille, } \\
\text { volontaires) } \\
\text { Liban, juill.-sept. } \\
2010\end{array}$ & $\begin{array}{l}\text { Humaine } \\
\text { A/Brisbane/59/ } \\
04 \text { (H1N1) } \\
\text { A/California/04/ } \\
09 \text { (H1N1) } \\
\text { A/Brisbane/10/ } \\
07 \text { (H3N2) } \\
\text { Aviaire } \\
\text { Sous-types H4-H16 }\end{array}$ & $\begin{array}{l}\text { MN (positif à des dilutions } \geq 1: 10, \\
\text { testé en double), IH (globules } \\
\text { rouges du cheval, positif pour les } \\
\text { échantillons MN et la réactivité } \\
\text { croisée) } \\
\text { Le groupe témoin avait des titres } \\
\text { plus élevés pour le virus grippal } \\
\text { saisonnier et le virus pandémique } \\
\text { H1N1, mais les groupes étaient } \\
\text { similaires pour le H3N2 } \\
5 \text { producteurs artisanaux se sont } \\
\text { révélés positifs avec les tests MN et } \\
\text { IH (3 pour le H4 et } 2 \text { pour le H11) } \\
\text { Les producteurs commerciaux } \\
\text { étaient plus susceptibles d'utiliser } \\
\text { de l'équipement de protection }\end{array}$ & III & $\begin{array}{l}\text { Passable } \\
\text { Les groupes ne } \\
\text { sont pas } \\
\text { entièrement } \\
\text { comparables }\end{array}$ \\
\hline
\end{tabular}




\begin{tabular}{|c|c|c|c|c|c|c|}
\hline \multicolumn{7}{|c|}{ PERSONNES AVEC UNE EXPOSITION PROFESSIONNELLE AUX POPULATIONS AVICOLES } \\
\hline Étude & $\begin{array}{l}\text { Modèle } \\
\text { d'étude }\end{array}$ & Participants & Type de grippe & Principales conclusions & Niveau & Qualité \\
\hline $\begin{array}{l}\text { Khuntirat B.P. } \\
(2011)^{50}\end{array}$ & $\begin{array}{l}\text { Séroprévalence } \\
\text { transversale }\end{array}$ & $\begin{array}{l}\mathrm{N}=800 \\
\text { Les villageois } \\
\text { de } \geq 20 \text { ans des } \\
\text { régions rurales } \\
\text { de la Thaillande } \\
\text { atteints par la grippe } \\
\text { aviaire hautement } \\
\text { pathogénique } \\
\text { (la plupart des } \\
\text { villageois élèvent de } \\
\text { petits troupeaux de } \\
\text { volaille domestique, } \\
\text { p. ex. le poulet, le } \\
\text { canard et la caille) } \\
\text { Thaillande, } \\
\text { avr.-oct. } 2008\end{array}$ & $\begin{array}{l}8 \text { souches humaines } \\
\text { (H1N1, H3N2, } \\
\text { H5N1, H9N2) } \\
16 \text { souches aviaires } \\
\text { (H1N1, H2N2, } \\
\text { H4N6, H5N2, H6N1, } \\
\text { H6N2, H7N2, H7N7, } \\
\text { H8N4, H9N2, } \\
\text { H10N4, H10N7, } \\
\text { H11N9, H12N5) } \\
2 \text { souches porcines } \\
\text { (H1N1, H3N2) }\end{array}$ & 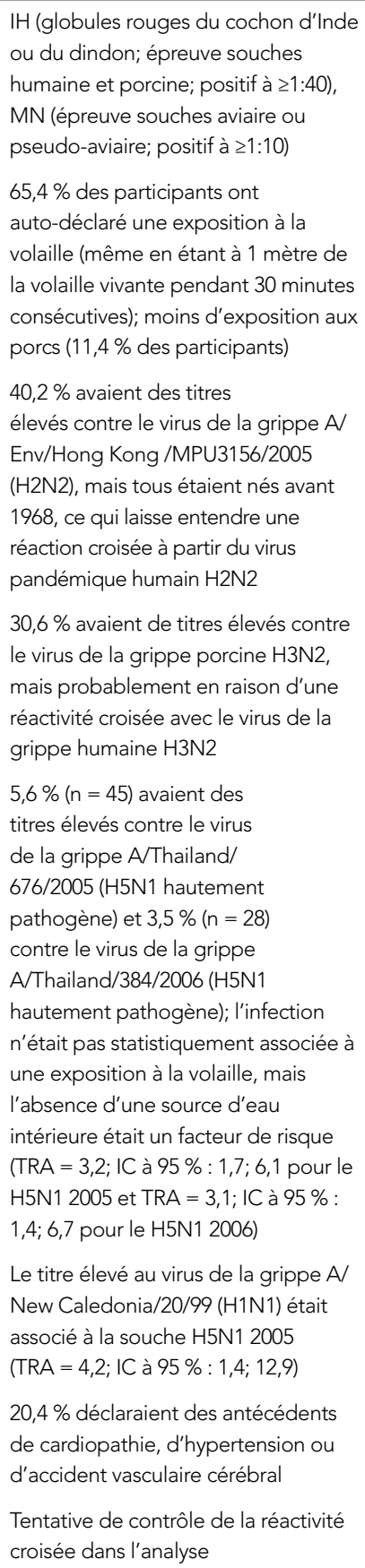 & III & Bon \\
\hline
\end{tabular}




\begin{tabular}{|c|c|c|c|c|c|c|}
\hline \multicolumn{7}{|c|}{ PERSONNES AVEC UNE EXPOSITION PROFESSIONNELLE AUX POPULATIONS AVICOLES } \\
\hline Étude & $\begin{array}{l}\text { Modèle } \\
\text { d'étude }\end{array}$ & Participants & Type de grippe & Principales conclusions & Niveau & Qualité \\
\hline $\begin{array}{l}\text { Koopmans M. } \\
(2004)^{51}\end{array}$ & $\begin{array}{l}\text { Descriptif } \\
\text { (surveillance des } \\
\text { éclosions) }\end{array}$ & $\begin{array}{l}\text { Échelle de la } \\
\text { population } \\
\mathrm{N}=453 \text { cas signalés } \\
\text { Personnes ayant un } \\
\text { contact direct avec la } \\
\text { volaille ou les } \\
\text { produits de volaille } \\
\text { qui auraient pu être } \\
\text { infectées par le H7 } \\
\text { ou ayant eu un } \\
\text { contact étroit avec } \\
\text { une personne } \\
\text { atteinte du H7 } \\
\text { Pays-Bas, } 2003\end{array}$ & $\begin{array}{l}\text { Aviaire } \\
\mathrm{H} 7\end{array}$ & 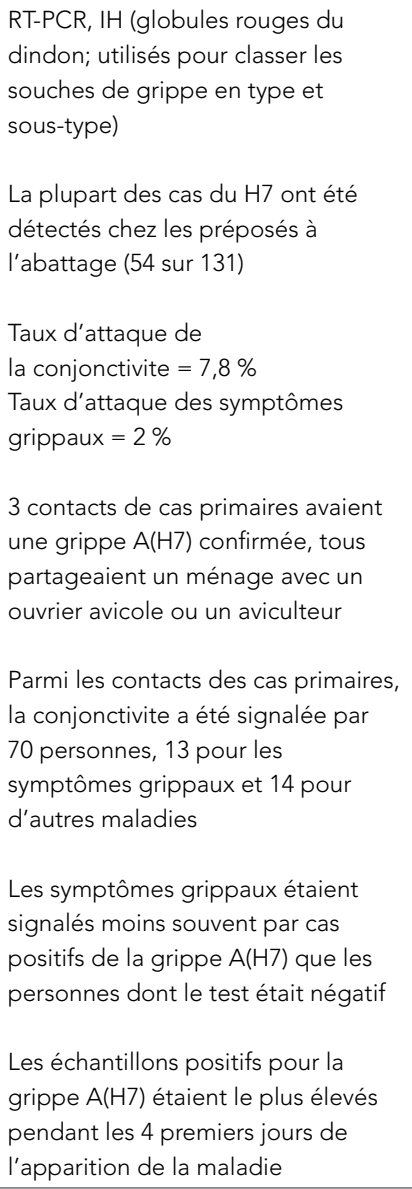 & III & Bon \\
\hline Kwon D. $(2012)^{15}$ & $\begin{array}{l}\text { Descriptif } \\
\text { (Surveillance des } \\
\text { éclosions avec } \\
\text { test sérologique- } \\
\text { échantillons } \\
\text { simples de } 1576 \\
\text { personnes, } \\
\text { échantillons } \\
\text { jumelés de } 936 \\
\text { personnes) }\end{array}$ & $\begin{array}{l}\mathrm{N}=2512 \text { (3 } 448 \\
\text { échantillons) } \\
\text { Personnes travaillant } \\
\text { dans des fermes } \\
\text { avicoles ou } \\
\text { effectuant l'abattage } \\
\text { des oiseaux au cours } \\
\text { des éclosions de } \\
\text { 2003-2004 } \\
\text { Corée du Sud, } \\
\text { 2003-2004 }\end{array}$ & $\begin{array}{l}\text { Aviaire } \\
\mathrm{H} 5 \mathrm{~N} 1\end{array}$ & $\begin{array}{l}\text { MN (positif si > 80, au moins } \\
2 \text { essais indépendants) avec un test } \\
\text { de confirmation par IH (cheval) ou } \\
\text { un test Western Blot propre au H5 } \\
9 \text { cas positifs au MN (4 échantillons } \\
\text { simples, } 5 \text { échantillons jumelés); } \\
2 \text { cas positifs par IH, mais tous les } \\
9 \text { cas positifs par Western Blot; tous } \\
\text { étaient des préposés à l'abattage }\end{array}$ & III & $\begin{array}{l}\text { Bon } \\
\text { Réactivité croisée } \\
\text { non évaluée en } \\
\text { raison d'un } \\
\text { échantillon limité } \\
\text { de sérum }\end{array}$ \\
\hline
\end{tabular}




\begin{tabular}{|c|c|c|c|c|c|c|}
\hline \multicolumn{7}{|c|}{ PERSONNES AVEC UNE EXPOSITION PROFESSIONNELLE AUX POPULATIONS AVICOLES } \\
\hline Étude & $\begin{array}{l}\text { Modèle } \\
\text { d'étude }\end{array}$ & Participants & Type de grippe & Principales conclusions & Niveau & Qualité \\
\hline Leibler J.H. $(2011)^{52}$ & $\begin{array}{l}\text { Séroprévalence } \\
\text { transversale } \\
\text { ( } 2 \text { points } \\
\text { temporels) }\end{array}$ & $\begin{array}{l}\mathrm{N}=99 \\
\mathrm{n}_{\text {ouvrier }}=24 \\
\mathrm{n}_{\text {témoin }}=75 \\
\text { Échantillon de } \\
\text { commodité des } \\
\text { ouvriers avicoles et } \\
\text { des résidents de la } \\
\text { localité } \\
\text { É.-U., 2003-2005 }\end{array}$ & $\begin{array}{l}\text { Humaine } \\
\text { A/New Caledonia/ } \\
\text { 20/99 (H1N1) } \\
\text { A/Panama/2007/ } \\
99 \text { (H3N2) } \\
\text { Aviaire } \\
\text { A/Duck/Cz/1/ } \\
56 \text { (H4N6) } \\
\text { A/Chucker/MN/ } \\
\text { 14591-7/98 (H5N2) } \\
\text { A/Turkey/MA/ } \\
65 \text { (H6N2) } \\
\text { A/Turkey/NA/ } \\
4529 / 02 \text { (H7N2) } \\
\text { A/Turkey/MN/ } \\
\text { 38391-6/95 (H9N2) } \\
\text { A/Chicken/DE/ } \\
\text { 04 (H7N2) }\end{array}$ & $\begin{array}{l}\text { IH (cochon d'Inde), MN (dépisté à } \\
\text { une dilution de 1:10) } \\
\text { Aucune preuve d'infection par un } \\
\text { virus de grippe aviaire n'a été } \\
\text { découverte } \\
\text { Prévalence élevée du H1N1 et du } \\
\text { H3N2 chez les ouvriers avicoles et } \\
\text { les membres de la localité }\end{array}$ & $\|-3$ & $\begin{array}{l}\text { Passable } \\
\text { L'échantillon de } \\
\text { commodité peut } \\
\text { avoir raté des } \\
\text { personnes } \\
\text { atteintes par } \\
\text { l'éclosion de la } \\
\text { grippe aviaire en } \\
2004\end{array}$ \\
\hline Lu $(2008)^{53}$ & $\begin{array}{l}\text { Séroprévalence } \\
\text { transversale (les } \\
\text { cas positifs au } \\
\text { H5N1 ont été } \\
\text { suivis pendant un } \\
\text { an) }\end{array}$ & $\begin{array}{l}\mathrm{N}=1214 \\
\mathrm{n}_{\text {professionnel }}=231 \\
\mathrm{n}_{\text {général }}=983 \\
\text { Exposés dans le } \\
\text { cadre de leur travail } \\
\text { (élevant, vendant et } \\
\text { abattant des poulets } \\
\text { et des canards) et } \\
\text { population générale } \\
\text { (ne s'adonnant pas à } \\
\text { des activités où sont } \\
\text { manipulés des } \\
\text { poulets ou des } \\
\text { canards vivants) dont } \\
\text { des membres sont } \\
\text { choisis aléatoirement } \\
\text { à partir de trois des } \\
\text { neuf régions } \\
\text { atteintes par les } \\
\text { éclosions du H5N1 } \\
\text { Chine, avr.-juin } 2004\end{array}$ & $\begin{array}{l}\text { Humaine } \\
\text { A/New Caledonia/ } \\
\text { 20/99 (H1N1) } \\
\text { A/Panama/2007/ } \\
99 \text { (H3N2) } \\
\text { Aviaire } \\
\text { A/goose/ } \\
\text { Guangdong/ } \\
\text { 1/96 (H5N1) } \\
\text { A/African/starling/ } \\
\text { Englan-q/983/ } \\
79 \text { (H7N7) } \\
\text { A/chicken/ } \\
\text { Shanghi/10/ } \\
01 \text { (H9N2) }\end{array}$ & $\begin{array}{l}\text { IH (globules rouges du poulet } \\
\text { utilisés pour détecter toutes les } \\
\text { souches; positif si les titres } \geq 1: 20 \text { ), } \\
\text { MN utilisé pour vérifier un } \\
\text { échantillon de résultats positifs du } \\
\text { IH (positif si les titres } \geq 1: 20 \text { ) } \\
\text { Résultats positifs par IH : } \\
\text { H1N1 - 31,22 \% ( }=379 \text { ) } \\
\text { H3N2 - 71,75 \% ( }=871 \text { ) } \\
\text { H5N1 - 2,47 \% ( } n=30 \text { ) } \\
\text { H7N7 - 0,08 \% ( } n=1 \text { ) } \\
\text { H9N2 - 4,86 \% ( } n=59 \text { ) } \\
1 \text { cas du H5N1 était encore positif } \\
\text { une année après (titre de 1:40), alors } \\
\text { que tous les autres cas aviaires } \\
\text { positifs sont devenus négatifs } \\
\text { Le taux de cas positifs exposés dans } \\
\text { le cadre de leur travail était } \\
\text { légèrement supérieur pour le H5N1 } \\
\text { (3,03 \% contre } 2,34 \%, p>0,05 \text { ), } \\
\text { supérieur pour le H9N2 ( } 9,52 \% \\
\text { contre } 3,76 \%, p<0,01 \text { ) et on ne } \\
\text { comptait qu'un seul cas positif pour } \\
\text { le H7N7 } \\
\text { Les résultats du test MN ont été } \\
\text { positivement corrélés avec les } \\
\text { résultats du test IH }\end{array}$ & II-3 & $\begin{array}{l}\text { Bon } \\
\text { Réactivité croisée } \\
\text { non prise en } \\
\text { compte }\end{array}$ \\
\hline
\end{tabular}




\begin{tabular}{|c|c|c|c|c|c|c|}
\hline \multicolumn{7}{|c|}{ PERSONNES AVEC UNE EXPOSITION PROFESSIONNELLE AUX POPULATIONS AVICOLES } \\
\hline Étude & $\begin{array}{l}\text { Modèle } \\
\text { d'étude }\end{array}$ & Participants & Type de grippe & Principales conclusions & Niveau & Qualité \\
\hline Ogata T. $(2008)^{54}$ & $\begin{array}{l}\text { Sérologie } \\
\text { transversale } \\
\text { (échantillons de } \\
\text { sérum jumelés } \\
\text { variant entre } \\
4 \text { semaines et } \\
2 \text { mois d'écart au } \\
\text { moins) }\end{array}$ & $\begin{array}{l}\mathrm{N}=257 \\
\text { Ouvriers avicoles des } \\
\text { fermes avicoles } \\
\text { classées séroposi- } \\
\text { tives pour le H5N2 } \\
\text { Japon, juin-nov. } 2005\end{array}$ & $\begin{array}{l}\text { Aviaire } \\
\text { A/Chicken/ } \\
\text { lbaraki/1/ } \\
2005 \text { (H5N2) }\end{array}$ & $\begin{array}{l}\text { MN (positif si le titre } \geq 1: 40 \text { dans des } \\
\text { échantillons de sérum jumelés) } \\
\text { TRA ajusté pour la positivité au } \\
\text { H5N2 chez les ouvriers âgés de plus } \\
\text { de } 40 \text { ans : } 4,6 \text { (IC à } 95 \%: 1,6 ; 13,7 \text { ) } \\
\text { TRA ajusté pour la positivité au } \\
\text { H5N2 chez les ouvriers avec des } \\
\text { antécédents de la vaccination } \\
\text { contre la grippe saisonnière : } 3,1 \text { (IC } \\
\text { à } 95 \% \text { : 1,6; } 6,1 \text { ) } \\
\text { Ajusté selon le sexe, l'âge, le } \\
\text { nombre d'ouvriers à la ferme ou les } \\
\text { antécédents de la vaccination } \\
\text { contre la grippe saisonnière }\end{array}$ & $\|-3$ & $\begin{array}{l}\text { Passable } \\
\text { Le moment de } \\
\text { l'infection à la } \\
\text { ferme avicole } \\
\text { était inconnu; } \\
17 \% \text { des } \\
\text { participants } \\
\text { exclus de } \\
\text { l'analyse en raison } \\
\text { de données } \\
\text { manquantes; } \\
\text { l'utilisation du } \\
\text { test MN } \\
\text { seulement peut } \\
\text { ne pas suffire }\end{array}$ \\
\hline Ortiz E.J. $(2007)^{55}$ & $\begin{array}{l}\text { Séroprévalence } \\
\text { transversale } \\
\text { (échantillon } \\
\text { simple de sérum) }\end{array}$ & $\begin{array}{l}N=150 \\
n_{\text {exposé }}=133 \\
n_{\text {non exposé }}=17 \\
\text { Ouvriers des fermes } \\
\text { avicoles } \\
\text { Pérou, } 2006\end{array}$ & $\begin{array}{l}\text { Humaine } \\
\text { A/New Caledonia/ } \\
\text { 20/99 (H1N1) } \\
\text { A/Nanchang/ } \\
\text { 933/95 (H3N2) } \\
\text { A/Panama/ } \\
\text { 2007/99 (H3N2 } \\
\text { Aviaire } \\
9 \text { sous-types H4-H12 }\end{array}$ & $\begin{array}{l}\text { IH (globules rouges du cochon } \\
\text { d'Inde) pour évaluer la réactivité } \\
\text { croisée (les dilutions ont commencé } \\
\text { à 1:10), MN (positif à } \geq 1: 80 \text { ) } \\
\text { Prévalence du virus de la grippe } \\
\text { aviaire faible dans les deux groupes } \\
\text { Un sujet exposé à la volaille avait un } \\
\text { titre de } 1: 10 \text { contre le virus aviaire } \\
\text { H5; et un autre ouvrier, contre le } \\
\text { virus aviaire } \mathrm{H} 12\end{array}$ & III & $\begin{array}{l}\text { Bon } \\
\text { L'exploitation } \\
\text { agricole étudiée } \\
\text { avait un bon } \\
\text { programme de } \\
\text { surveillance actif } \\
\text { pour corroborer } \\
\text { les conclusions }\end{array}$ \\
\hline Ortiz J.R. $(2007)^{56}$ & $\begin{array}{l}\text { Enquête } \\
\text { descriptive } \\
\text { sur la } \\
\text { séroprévalence }\end{array}$ & $\begin{array}{l}\mathrm{N}=295 \\
\text { Ouvriers avicoles de } \\
\text { sites avec volaille } \\
\text { atteinte du virus } \\
\text { H5N1 soupçonné ou } \\
\text { confirmé (ouvriers } \\
\text { agricoles, travailleurs } \\
\text { dans un marché, } \\
\text { préposés à } \\
\text { l'abattage), } \\
\text { vétérinaires des } \\
\text { cliniques pour la } \\
\text { volaille, employés de } \\
\text { laboratoire du } \\
\text { National Veterinary } \\
\text { Research Institute } \\
\text { Nigeria, } \\
\text { mars-avr. } 2006\end{array}$ & $\begin{array}{l}\text { Humaine } \\
\text { A/New York/ } \\
\text { 55/2005 (H3N2) } \\
\text { Aviaire } \\
\text { A/chicken/Nigeria/ } \\
\text { 246/06 (H5N1) } \\
\text { A/chicken/Nigeria/ } \\
\text { 42/2006 (H5N1) }\end{array}$ & $\begin{array}{l}\text { Test MN (positif si les titres } \geq 1: 80 \text { ) à } \\
\text { l'aide du test IH (globules rouges du } \\
\text { cheval) } \\
\text { Aucune association importante pour } \\
\text { I'utilisation de l'EPI ou le lavage de } \\
\text { mains chez les ouvriers avicoles } \\
\text { Aucun échantillon positif découvert } \\
\text { dans la population étudiée pour le } \\
\text { H5N1, mais } 97 \% \text { avaient des titres } \\
\text { neutralisants } \geq 1: 80 \text { contre le virus } \\
\text { humain circulant H3N2 }\end{array}$ & III & $\begin{array}{l}\text { Passable } \\
\text { La confirmation } \\
\text { de l'infection à } \\
\text { H5N1 dans la } \\
\text { volaille était } \\
\text { limitée; } \\
\text { Échantillon de } \\
\text { commodité avec } \\
\text { un effort déployé } \\
\text { pour trouver les } \\
\text { employés absents } \\
\text { ou malades }\end{array}$ \\
\hline
\end{tabular}




\begin{tabular}{|c|c|c|c|c|c|c|}
\hline \multicolumn{7}{|c|}{ PERSONNES AVEC UNE EXPOSITION PROFESSIONNELLE AUX POPULATIONS AVICOLES } \\
\hline Étude & $\begin{array}{l}\text { Modèle } \\
\text { d'étude }\end{array}$ & Participants & Type de grippe & Principales conclusions & Niveau & Qualité \\
\hline Pawar S.D. $(2012)^{57}$ & $\begin{array}{l}\text { Enquête } \\
\text { descriptive } \\
\text { sur la } \\
\text { séroprévalence }\end{array}$ & $\begin{array}{l}\mathrm{N}_{\text {ouvrier }}=338 \\
\mathrm{~N}_{\text {échantillon témoin }}=249 \\
\text { Ouvriers dans les } \\
\text { poulaillers et les } \\
\text { fermes avicoles; } \\
\text { Échantillons de } \\
\text { sérum de la } \\
\text { population générale } \\
\text { utilisés pour établir } \\
\text { les niveaux } \\
\text { d'anticorps de } \\
\text { départ } \\
\text { Inde, juill.-déc. } 2010\end{array}$ & $\begin{array}{l}\text { Aviaire } \\
\text { A/chicken/ } \\
\text { India/NIV/ } \\
\text { 99321/09 (H9N2) }\end{array}$ & $\begin{array}{l}\text { Test IH (globules rouges du dindon), } \\
\text { test MN ; Résultats des tests } \\
\text { présentés pour les seuils de } \\
\text { coupure } \geq 40, \geq 80 \text { et } \geq 160 \\
\text { Aucun échantillon positif dans le } \\
\text { sérum de départ au seuil de } \\
\text { coupure } \geq 40 \\
21 \text { personnes sur } 338 \text { ( } 6,2 \% \text { ) étaient } \\
\text { positives par IH ou MN d'après le } \\
\text { seuil de coupure } \geq 40 \\
4 \text { personnes par IH et } 5 \text { personnes } \\
\text { par MN étaient positives au seuil de } \\
\text { coupure } \geq 80 \text {; et } 2 \text { personnes et } \\
1 \text { personne étaient positives à } \geq 160 \\
\text { par IH et MN respectivement }\end{array}$ & III & Bon \\
\hline Puzelli S. $(2005)^{58}$ & $\begin{array}{l}\text { Enquête } \\
\text { sérologique } \\
\text { descriptive }\end{array}$ & $\begin{array}{l}\text { Néchantillon de } \\
\text { sérum = 983 } \\
\text { Ouvriers dans } \\
\text { plusieurs catégories } \\
\text { de travail dans les } \\
\text { fermes } \\
\text { Italie, 1999-2003 }\end{array}$ & $\begin{array}{l}\text { Aviaire } \\
\text { H7N1 } \\
\text { H7N3 }\end{array}$ & $\begin{array}{l}\text { Test IH (globules rouges du cheval) } \\
\text { et test MN avec l'épreuve du } \\
\text { Western Blot ou d'hémagglutinine } \\
\text { pour une confirmation positive }\end{array}$ & III & \\
\hline Santhia K. (2009) $)^{59}$ & $\begin{array}{l}\text { Enquête } \\
\text { descriptive sur la } \\
\text { séroprévalence } \\
\text { avec grappe } \\
\text { basée sur le } \\
\text { ménage }\end{array}$ & $\begin{array}{l}\mathrm{N}=841 \\
\mathrm{n}_{\text {ménage }}=291 \\
\mathrm{n}_{\text {marchand }}=87 \\
\text { Ménages participant } \\
\text { à l'élevage de la } \\
\text { volaille et un marché } \\
\text { de volaille vivante } \\
\text { Indonésie, } 2005\end{array}$ & $\begin{array}{l}\text { Aviaire } \\
\mathrm{H} 5 \mathrm{~N} 1\end{array}$ & $\begin{array}{l}\text { Test IH utilisé pour la volaille (positif } \\
\text { si les titres } \geq 20 \text { ), test MN utilisé } \\
\text { pour les humains et les porcs (positif } \\
\text { si les titres } \geq 80 \text { ) } \\
\text { La majorité des ménages avaient } \\
\text { des poulets et des porcs, des } \\
\text { poulets seulement, ou des poulets, } \\
\text { des canards et des porcs } \\
\text { Aucun poulet ou canard échan- } \\
\text { tillonné n'était positif pour le H5N1 } \\
\text { par RT-PCR; un canard était positif } \\
\text { pour le virus de la grippe H4 } \\
\text { Aucun des porcs évalués ( } \mathrm{n}=344 \text { ) } \\
\text { n'était positif pour le H5N1 par } \\
\text { RT-PCR et MN } \\
\text { Aucun des participants des } \\
\text { ménages n'était positif pour le } \\
\text { H5N1 par MN, malgré que } 57 \% \text { des } \\
\text { participants provenaient de villages } \\
\text { avec des antécédents d'éclosions } \\
\text { du H5N1 }\end{array}$ & III & Passable \\
\hline
\end{tabular}




\begin{tabular}{|c|c|c|c|c|c|c|}
\hline \multicolumn{7}{|c|}{ PERSONNES AVEC UNE EXPOSITION PROFESSIONNELLE AUX POPULATIONS AVICOLES } \\
\hline Étude & $\begin{array}{l}\text { Modèle } \\
\text { d'étude }\end{array}$ & Participants & Type de grippe & Principales conclusions & Niveau & Qualité \\
\hline Schultsz C. (2009) $)^{17}$ & $\begin{array}{l}\text { Enquête } \\
\text { descriptive } \\
\text { sur la } \\
\text { séroprévalence }\end{array}$ & $\begin{array}{l}\mathrm{N}=500 \\
\mathrm{n}_{\text {ouvrier }}=183 \\
\mathrm{n}_{\text {préposé à l'abattage }}=317 \\
\text { Ouvriers avicoles et } \\
\text { préposés à } \\
\text { l'abattage } \\
\text { Vietnam, 2004-2005 }\end{array}$ & $\begin{array}{l}\text { Aviaire } \\
\mathrm{H} 5 \mathrm{~N} 1\end{array}$ & $\begin{array}{l}\text { Test MN contre } 2 \text { groupes de } \\
\text { souches grippales avec des } \\
\text { échantillons positifs (titres } \geq 1: 80 \text { ) } \\
\text { testés à nouveau par IH (globules } \\
\text { rouges du cheval; positif si les titres } \\
\geq 1: 80 \text { ); Réactivité croisée avec les } \\
\text { virus de la grippe A évalués } \\
\text { (multiplication par quatre ou } \\
\text { diminution plus grande du titre } \\
\text { contre le H5 dans le sérum traité) } \\
\text { Aucun des ouvriers n'affichait de } \\
\text { titre positif contre le H5N1 } \\
\text { Un petit nombre de préposés à } \\
\text { l'abattage étaient positifs dans } \\
\text { certains tests MN, mais certains } \\
\text { échantillons avaient une réactivité } \\
\text { croisée soupçonnée au H1 } \\
3 \text { préposés à l'abattage présentai- } \\
\text { ent des titres IH de } 1: 20 \text {, de } 1: 40 \text { et } \\
\text { de } 1: 200 \text { - Ils travaillaient dans } \\
\text { I'abattage depuis plus d'un an }\end{array}$ & III & Passable \\
\hline Shafir S.C. $(2012)^{19}$ & $\begin{array}{l}\text { Enquête } \\
\text { descriptive } \\
\text { sur la } \\
\text { séroprévalence }\end{array}$ & $\begin{array}{l}\mathrm{N}=401 \\
\text { Manipulateurs } \\
\text { d'oiseaux migrateurs } \\
\text { É.-U., 2008-2010 }\end{array}$ & $\begin{array}{l}\text { Humaine } \\
\text { pH1N1 } \\
\text { Aviaire } \\
2008 \\
\text { H5N2, H7N2, H9N2 } \\
2009 \\
\text { H5N2, H7N3 } \\
2010 \\
\text { H5N2, H7N2 }\end{array}$ & $\begin{array}{l}\text { Test MN (positif si les titres } \geq 1: 40 \text { ) } \\
\text { Seule une personne s'est avérée } \\
\text { positive pour le H5N2 } \\
\text { Aucune preuve de virus de la grippe } \\
\text { aviaire et de co-infection par pH1N1 }\end{array}$ & III & Passable \\
\hline Vong S. $(2006)^{20}$ & $\begin{array}{l}\text { Enquête } \\
\text { descriptive } \\
\text { sur la } \\
\text { séroprévalence }\end{array}$ & $\begin{array}{l}\mathrm{N}_{\text {ménage }}=93 \text { ( } 351 \\
\text { participants) } \\
\text { Village rural avec } \\
\text { décès causé par le } \\
\text { H5N1 confirmé } \\
\text { Cambodge, } 2005\end{array}$ & $\begin{array}{l}\text { Aviaire } \\
\text { H5N1 }\end{array}$ & $\begin{array}{l}\text { RT-PCR, test MN (positif si les titres } \\
\geq 80 \text { ) avec le test de confirmation } \\
\text { Western Blot } \\
\text { Aucun des participants n'a déclaré } \\
\text { avoir une maladie fébrile ou } \\
\text { respiratoire pendant la période } \\
\text { visée; et aucun ne s'est révélé positif } \\
\text { pour le H5N1, en dépit d'un contact } \\
\text { régulier de haute intensité avec la } \\
\text { volaille ou les porcs dans la majeure } \\
\text { partie de la population } \\
\text { Les poulets abattus ne constituaient } \\
\text { pas un facteur de risque important } \\
\text { d'après la vérification des } \\
\text { expositions découvertes comme } \\
\text { substantielles dans une analyse } \\
\text { multivariable (p. ex. le nettoyage } \\
\text { des cages ou des stalles, la } \\
\text { manipulation de la volaille, l'achat } \\
\text { de la volaille vivante, le nettoyage } \\
\text { des plumes de volaille) }\end{array}$ & III & $\begin{array}{l}\text { Passable } \\
\text { Potentiel pour un } \\
\text { biais de rappel; } \\
\text { ne peut évaluer le } \\
\text { degré de } \\
\text { classification } \\
\text { erronée sans la } \\
\text { confirmation } \\
\text { d'une infection } \\
\text { par le virus H5N1 } \\
\text { chez la volaille }\end{array}$ \\
\hline
\end{tabular}




\begin{tabular}{|c|c|c|c|c|c|c|}
\hline \multicolumn{7}{|c|}{ PERSONNES AVEC UNE EXPOSITION PROFESSIONNELLE AUX POPULATIONS AVICOLES } \\
\hline Étude & $\begin{array}{l}\text { Modèle } \\
\text { d'étude }\end{array}$ & Participants & Type de grippe & Principales conclusions & Niveau & Qualité \\
\hline Wang M. (2009) 60 & $\begin{array}{l}\text { Enquête } \\
\text { descriptive } \\
\text { sur la } \\
\text { séroprévalence }\end{array}$ & $\begin{array}{l}\mathrm{N}=2191 \\
\text { Personnes en santé } \\
\text { de plusieurs lieux de } \\
\text { travail (détaillants en } \\
\text { volaille, grossistes en } \\
\text { volaille, ouvriers dans } \\
\text { des entreprises } \\
\text { d'élevage de la } \\
\text { volaille à grande } \\
\text { échelle, aviculteurs } \\
\text { dans des fermes } \\
\text { avicoles rurales à } \\
\text { petite échelle, } \\
\text { ouvriers dans des } \\
\text { entreprises d'élevage } \\
\text { de porcs, détaillants } \\
\text { de marchandises } \\
\text { autres que la volaille } \\
\text { dans un marché } \\
\text { d'alimentation, } \\
\text { population générale) } \\
\text { Chine, mars 2007- } \\
\text { juill. 2008 }\end{array}$ & $\begin{array}{l}\text { Aviaire } \\
\text { H5N1 } \\
\text { H5N2 } \\
\text { H9N2 }\end{array}$ & $\begin{array}{l}\text { Test IH, test MN; Conditions pour } \\
\text { un titre positif non établies } \\
\text { Prévalence de l'anticorps anti-H5 et } \\
\text { anti-H9 était de } 0,2 \% \text { et de } 4,5 \% \text {, } \\
\text { respectivement, dans la population } \\
\text { étudiée } \\
\text { Tous les anti-H5-positifs chez les } \\
\text { détaillants ou grossistes en volaille; } \\
\text { les anti-H9-positifs ont été } \\
\text { découverts dans tous les groupes } \\
\text { étudiés } \\
\text { Taux positifs dans les anti-H5 plus } \\
\text { faibles que dans les anti-H9 chez les } \\
\text { détaillants en volaille }(0,8 \% \text { contre } \\
15,5 \%, \mathrm{P}<0,001) \text { et les grossistes } \\
\text { en volaille (0,8 \% contre } 6,6 \% \text {, } \\
\text { p = 0,001) }\end{array}$ & III & Passable \\
\hline Yamazaki Y. (2009) ${ }^{61}$ & $\begin{array}{l}\text { Enquête } \\
\text { descriptive sur la } \\
\text { séroprévalence }\end{array}$ & $\begin{array}{l}\mathrm{N}=266 \\
\mathrm{n}_{\text {région d'éclosion }}=114 \\
\mathrm{n}_{\text {pop. générale }}=100 \\
\mathrm{n}_{\text {ouvrier }}=52 \\
\text { Habitants dans la } \\
\text { région où est } \\
\text { survenue l'éclosion } \\
\text { du H5N2; population } \\
\text { générale au Japon; } \\
\text { employés dans } \\
\text { l'industrie avicole ou } \\
\text { dans des emplois } \\
\text { connexes, ou qui y } \\
\text { étaient } \\
\text { Japon, } \\
\text { mai-août } 2006\end{array}$ & $\begin{array}{l}\text { Aviaire } \\
\mathrm{H} 5 \mathrm{~N} 2\end{array}$ & $\begin{array}{l}\text { Test MN (positif si les titres } \geq 1: 40 \text { ), } \\
\text { test IH (globules rouges du cheval; } \\
\text { positif si les titres } \geq 1: 40 \text { ) } \\
8 \text { échantillons de la région } \\
\text { d'éclosion, } 4 \text { de la population } \\
\text { générale, } 8 \text { ouvriers avicoles ont } \\
\text { affiché un titre de } M N \geq 40 \\
9 \text { échantillons de la région } \\
\text { d'éclosion, } 2 \text { de la population } \\
\text { générale, } 2 \text { ouvriers avicoles ont } \\
\text { affiché un titre IH } \geq 40 \\
\text { La séropositivité était liée à l'âge } \\
\text { chez les ouvriers avicoles ( } p=0,038 \text { ) } \\
\text { Cas positifs significatifs chez les } \\
\text { ouvriers avicoles comparativement à } \\
\text { la population générale ( } p=0,018 \text { ) }\end{array}$ & III & Bon \\
\hline
\end{tabular}




\begin{tabular}{|c|c|c|c|c|c|c|}
\hline \multicolumn{7}{|c|}{ PERSONNES AVEC UNE EXPOSITION PROFESSIONNELLE AUX POPULATIONS PORCINES } \\
\hline Étude & $\begin{array}{l}\text { Modèle } \\
\text { d'étude }\end{array}$ & Participants & Type de grippe & Principales conclusions & Niveau & Qualité \\
\hline $\begin{array}{l}\text { Ayora-Talavera G. } \\
(2005)^{62}\end{array}$ & $\begin{array}{l}\text { Dépistage } \\
\text { sérologique } \\
\text { Échantillon de } \\
\text { commodité (tout } \\
\text { résident ayant } \\
\text { consulté les } \\
\text { services de santé } \\
\text { pour un problème } \\
\text { et tests de } \\
\text { laboratoire requis) }\end{array}$ & $\begin{array}{l}\mathrm{N}=115 \\
\text { Indigènes Maya } \\
\mathrm{d}^{\prime} u n e \text { localité } \\
\text { agricole rurale } \\
\text { (porcs errant dans } \\
\text { la ville et } \\
\text { pénétrant } \\
\text { librement dans les } \\
\text { maisons) } \\
\text { Mexique, } 2000\end{array}$ & $\begin{array}{l}\text { Humaine } \\
\text { A/Bayern/7/95 (H1N1) } \\
\text { A/Sydney/5/97 (H3N2) } \\
\text { Porcine } \\
\text { A/Swine/ } \\
\text { Wisconsin/238/97 } \\
\text { (H1N1) } \\
\text { A/Swine/ } \\
\text { Minnesota/593/99 } \\
\text { (H3N2 réassorti) }\end{array}$ & $\begin{array}{l}\text { IH (globules rouges du poulet; } \\
\text { positif si le titre } \geq 1: 40) \\
\text { Risque relatif d'être séropositif à } \\
\text { partir d'une exposition aux porcs : } \\
\text { humaine } \mathrm{H} 1-1,93(1,2 ; 3,0) \\
\text { humaine } \mathrm{H} 3-0,88(0,55 ; 1,4) \\
\text { porcine } \mathrm{H} 1-0,6(0,08 ; 4,2) \\
\text { porcine } \mathrm{H} 3-1,0(0,62 ; 1,6) \\
\text { Les taux de réactivité étaient élevés } \\
\text { pour les virus de grippe du } \\
\text { sous-type } \mathrm{H} 3 \text { et les plus élevés pour } \\
\text { le virus de grippe A/Sw/Minnesota }\end{array}$ & III & $\begin{array}{l}\text { Passable } \\
\text { Prévalence } \\
\text { d'infection chez } \\
\text { les porcs } \\
\text { inconnue }\end{array}$ \\
\hline $\begin{array}{l}\text { Beaudoin A. } \\
(2010)^{36}\end{array}$ & $\begin{array}{l}\text { Enquête } \\
\text { descriptive avec } \\
\text { dépistage } \\
\text { sérologique }\end{array}$ & $\begin{array}{l}\mathrm{N}=27 \\
\mathrm{n}_{\text {exposé }}=16 \\
\mathrm{n}_{\text {non exposé }}=9 \\
\text { Employés de deux } \\
\text { grandes fermes } \\
\text { porcines } \\
\text { comparables } \\
\text { (antécédents de } \\
\text { la grippe porcine à } \\
\text { la ferme connus); } \\
\text { Les personnes } \\
\text { exposées } \\
\text { travaillaient à la } \\
\text { ferme avec des } \\
\text { porcs positifs pour } \\
\text { le H2 Sept.-déc. } \\
2006\end{array}$ & $\begin{array}{l}\text { Humaine } \\
\text { A/New } \\
\text { Caledonia/20/99 } \\
\text { (H1N1) } \\
\text { A/Panama/2007/99 } \\
\text { (H3N2) } \\
\text { Porcine } \\
\text { A/Sw/ } \\
\text { MO/4296424/2006 } \\
\text { (H2N3) }\end{array}$ & $\begin{array}{l}\text { IH (protocole des CDC; positif si les } \\
\text { titres } \geq 1: 40 ; \text { réactivité croisée } \\
\text { évaluée avec les souches humaines } \\
\mathrm{H} 1 \text { et H3); MN (positif si les titres } \\
\geq 1: 40 \text { ) } \\
\text { Quatre participants étaient positifs } \\
\text { pour le H2N3 (trois nés avant 1968, } 1 \\
\text { avec l'année de naissance inconnue), } \\
\text { dont un seulement faisait partie du } \\
\text { groupe exposé (né en } 1949 \text { et la } \\
\text { séropositivité peut ne pas être liée à } \\
\text { une exposition récente) } \\
\text { Tous les ouvriers ont déclaré l'usage } \\
\text { d'une certaine forme d'EPI (p. ex. } \\
\text { bottes, masques, gants, vêtement } \\
\text { de protection), mais cela n'est pas } \\
\text { associé à la probabilité de } \\
\text { séropositivité }\end{array}$ & $\|-2$ & $\begin{array}{l}\text { Bon } \\
\text { Petits nombres; } \\
\text { Antécédents } \\
\text { d'infection } \\
\text { grippale connus }\end{array}$ \\
\hline Gerloff N.A. (2011) & $\begin{array}{l}\text { Dépistage } \\
\text { sérologique }\end{array}$ & $\begin{array}{l}\mathrm{N}=211 \\
\mathrm{~N}_{\text {échantillon témoin }}=224 \\
\text { Personnes en } \\
\text { santé avec une } \\
\text { exposition } \\
\text { professionnelle } \\
\text { passée ou } \\
\text { présente aux } \\
\text { porcs; Sérum } \\
\text { prélevé auprès de } \\
\text { la population } \\
\text { générale à titre } \\
\text { d'examen de } \\
\text { routine utilisé } \\
\text { comme dépistage } \\
\text { Luxembourg, } 2009\end{array}$ & $\begin{array}{l}\text { Humaine } \\
\text { A/Luxembourg/ } \\
\text { 43/2009 (pH1N1) } \\
\text { A/Luxembourg/ } \\
\text { 572/2008 } \\
\text { (H1N1 saisonnier) } \\
\text { Porcine } \\
\text { A/Swine/Belgium/ } \\
\text { 1/98 (H1N1 SIV } \\
\text { pseudo-aviaire) }\end{array}$ & $\begin{array}{l}\text { MN (protocole de l'OMS; dépistage } \\
\text { à partir de } \geq 1: 10 \text { ) } \\
\text { Les moyennes géométriques des } \\
\text { titres (MGT) étaient sensiblement } \\
\text { plus élevées chez les ouvriers de } \\
\text { porcheries que chez les témoins } \\
\text { pour le virus pandémique } \\
\text { Les MGT étaient plus élevées chez } \\
\text { les ouvriers de porcheries que chez } \\
\text { les témoins pour le virus de la } \\
\text { grippe porcine, mais n'étaient pas } \\
\text { statistiquement différentes } \\
\text { Être positif pour le virus de la grippe } \\
\text { porcine a accru le TRA d'être positif } \\
\text { pour le pH1N1 de 2,4 (1,3; } 4,3) \text { chez } \\
\text { les ouvriers de porcheries; Le TRA } \\
\text { s'est accru de } 6 \text { (2,9; } 12,6 \text { ) chez les } \\
\text { témoins }\end{array}$ & III & Bon \\
\hline
\end{tabular}




\begin{tabular}{|c|c|c|c|c|c|c|}
\hline \multicolumn{7}{|c|}{ PERSONNES AVEC UNE EXPOSITION PROFESSIONNELLE AUX POPULATIONS PORCINES } \\
\hline Étude & $\begin{array}{l}\text { Modèle } \\
\text { d'étude }\end{array}$ & Participants & Type de grippe & Principales conclusions & Niveau & Qualité \\
\hline Gray G.C. $(2007)^{63}$ & $\begin{array}{l}\text { Enquête } \\
\text { prospective avec } \\
\text { dépistage } \\
\text { sérologique }\end{array}$ & $\begin{array}{l}\mathrm{N}=803 \\
\mathrm{n}_{\text {exposé au porc AHS }}=707 \\
\mathrm{n}_{\text {non exposé au porc AHS }}= \\
80 \\
\mathrm{n}_{\text {témoin universitaire }}=79 \\
\text { Ouvriers de } \\
\text { porcheries de la } \\
\text { cohorte de } \\
\text { l'Agricultural } \\
\text { Health Study } \\
\text { (AHS); épouses et } \\
\text { participants } \\
\text { universitaires } \\
\text { utilisés comme } \\
\text { témoins } \\
\text { É.-U., 2004-2006 }\end{array}$ & $\begin{array}{l}\text { Humaine } \\
\text { A/New Caledonia/ } \\
\text { 20/99 (H1N1) } \\
\text { A/Panama/2007/ } \\
99 \text { (H3N2) } \\
\text { Porcine } \\
\text { A/swine/Wl/238/ } \\
97 \text { (H1N1) } \\
\text { A/swine/Wl/ } \\
\text { R33F/2011 (H1N2) }\end{array}$ & $\begin{array}{l}\text { IH (protocole des CDC, globules } \\
\text { rouges du cochon d'Inde utilisés } \\
\text { pour les souches humaines et } \\
\text { globules rouges du dindon utilisés } \\
\text { pour les souches porcines; positif } \\
\text { aux titres } \geq 1: 40 \text { pris en compte au } \\
\text { départ, mais le spectre a aussi été } \\
\text { évalué) } \\
>90 \% \text { des personnes exposées aux } \\
\text { porcs dans l'AHS travaillaient avec } \\
\text { des porcs depuis > } 10 \text { ans } \\
\text { À l'inscription: } \\
\text { Les personnes exposées aux porcs } \\
\text { avaient des titres plus élevés contre } \\
\text { les sous-types de grippe porcine } \\
\text { H1N1 que d'autres groupes } \\
\text { À comparer aux témoins universi- } \\
\text { taires, les personnes exposées aux } \\
\text { porcs avaient un risque accru pour le } \\
\text { virus de la grippe porcine H1N1 TRA } \\
\text { ajusté de } 54,9 \text { (13,0; } 232,6) ; \text { les } \\
\text { personnes non exposées aux porcs } \\
\text { avaient un TRA ajusté de } 28,2 \text { (6,1; } \\
\text { 130,1) } \\
\text { L'activité sérologique contre la } \\
\text { grippe porcine a été observée } \\
\text { durant la période de suivi avec } \\
\text { relativement peu de cas de } \\
\text { symptômes grippaux autodéclarés } \\
\text { Le virus de la grippe A/lowa/ } \\
\text { CEID23/05 a été isolé d'une } \\
\text { personne avec des symptômes }\end{array}$ & $\|-2$ & $\begin{array}{l}\text { Médiocre } \\
\text { Participation } \\
\text { volontaire; L'âge } \\
\text { est un facteur } \\
\text { statistiquement } \\
\text { important dans } \\
\text { l'analyse et il y a } \\
\text { une différence } \\
\text { dans l'âge moyen } \\
\text { entre les témoins } \\
\text { universitaires et } \\
\text { d'autres } \\
\text { participants }\end{array}$ \\
\hline
\end{tabular}




\begin{tabular}{|c|c|c|c|c|c|c|}
\hline \multicolumn{7}{|c|}{ PERSONNES AVEC UNE EXPOSITION PROFESSIONNELLE AUX POPULATIONS PORCINES } \\
\hline Étude & $\begin{array}{l}\text { Modèle } \\
\text { d'étude }\end{array}$ & Participants & Type de grippe & Principales conclusions & Niveau & Qualité \\
\hline Kitikoon P. $(2011)^{64}$ & $\begin{array}{l}\text { Dépistage } \\
\text { sérologique }\end{array}$ & $\begin{array}{l}\mathrm{N}=243 \\
\mathrm{n}_{\text {exposé }}=78 \\
\mathrm{n}_{\text {témoin }}=60 \\
\mathrm{n}_{\text {porc }}=85 \\
\text { Ouvriers de } \\
2 \text { exploitations } \\
\text { agricoles } \\
\text { commerciales; } \\
\text { témoins non } \\
\text { exposés recrutés } \\
\text { volontairement } \\
\text { dans un centre de } \\
\text { traitement du sang } \\
\text { ou dans un } \\
\text { hôpital; porcs } \\
\text { Thaïlande, } \\
\text { 2008-2009 }\end{array}$ & $\begin{array}{l}\text { Humaine } \\
\text { A/Thailand/CU41/ } \\
06 \text { (H1N1 saisonnier) } \\
\text { A/Nonthaburi/ } \\
\text { 102/09 (pH1N1) } \\
\text { Porcine } \\
\text { A/Swine/Thailand/ } \\
\text { CU-CB1/06 (H1N1) } \\
\text { A/Swine/Thailand/ } \\
\text { Cu-CHK4/09 (H1N2) }\end{array}$ & $\begin{array}{l}\text { IH (globules rouges du poulet pour } \\
\text { les virus swH1N1, swH1N2 et } \\
\text { huH1N1; globules rouges du dindon } \\
\text { pour le virus pH1N1; titres } \geq 40 \\
\text { considérés comme exposés } \\
50 \text { (92\%) des ouvriers des } \\
2 \text { exploitations avaient des anticorps } \\
\text { contre le virus de la grippe porcine } \\
\text { (SIV) circulant à l'endroit (ces } \\
\text { personnes comprenaient les } \\
\text { propriétaires, les ouvriers à la } \\
\text { porcherie, les vétérinaires, le } \\
\text { personnel du nettoyage et le } \\
\text { personnel administratif) } \\
\text { Comparativement au groupe } \\
\text { témoin, les ouvriers exposés avaient } \\
\text { un TRA de } 42,63 \text { (14,65; 124) pour les } \\
\text { anticorps élevés contre le SIV H1N1 } \\
\text { et un TRA de } 58 \text { (13,12; } 256,3 \text { ) contre } \\
\text { le SIV H1N2 }\end{array}$ & III & $\begin{array}{l}\text { Passable } \\
\text { Les témoins } \\
\text { volontaires } \\
\text { peuvent ne pas } \\
\text { représenter la } \\
\text { population } \\
\text { générale de base }\end{array}$ \\
\hline
\end{tabular}




\begin{tabular}{|c|c|c|c|c|c|c|}
\hline \multicolumn{7}{|c|}{ PERSONNES AVEC UNE EXPOSITION PROFESSIONNELLE AUX POPULATIONS PORCINES } \\
\hline Étude & $\begin{array}{l}\text { Modèle } \\
\text { d'étude }\end{array}$ & Participants & Type de grippe & Principales conclusions & Niveau & Qualité \\
\hline $\begin{array}{l}\text { Krumbholz A. } \\
(2010)^{65}\end{array}$ & $\begin{array}{l}\text { Enquête } \\
\text { prospective avec } \\
\text { dépistage } \\
\text { sérologique }\end{array}$ & $\begin{array}{l}\mathrm{N}=236 \\
\mathrm{n}_{\text {abatteurlinspecteur }}=50 \\
n_{\text {agriculteur }}=46 \\
n_{\text {véterinaire }}=22 \\
n_{\text {témoin }}=118 \\
\text { Professionnels } \\
\text { exposés aux porcs } \\
\text { dans le cadre de } \\
\text { leur travail; les } \\
\text { témoins non } \\
\text { exposés étaient } \\
\text { des donneurs de } \\
\text { sang appariés } \\
\text { d'après la } \\
\text { fréquence selon le } \\
\text { sexe et l'âge } \\
\text { Allemagne, } \\
\text { déc. } 2007 \text { à } \\
\text { avr. } 2009\end{array}$ & $\begin{array}{l}\text { Neuf souches } \\
\text { humaines et porcines }\end{array}$ & $\begin{array}{l}\text { Test IH (globules rouges du poulet } \\
\text { pour tous les virus sauf le virus } \mathrm{A} / \\
\text { Berlin/1/2003 qui a utilisé des } \\
\text { globules rouges du dindon; titre } \\
\text { élevé si } \geq 80 \text { et/ou augmentation par } \\
\text { facteur de quatre de la moyenne } \\
\text { géométrique des titres), test MN } \\
\text { pour confirmer les résultats IH, tests } \\
\text { ELISA propres au virus de la grippe } \\
\text { Prévalence des anticorps contre le } \\
\text { SIV comparativement aux témoins : } \\
\text { H1N1 } \\
\text { Personnes exposées }-2 / 118 \\
(1,7 \% ; 0,6 ; p=n . s .) \\
\text { Abatteurs }-2 / 50 \\
(4 \% ; 0,4,13,8 ; p=n . s .) \\
\text { Agriculteurs }-0 / 46 \\
(0 \% ; 0,7,8 ; p=n . s .) \\
\text { Vétérinaires }-0 / 22 \\
(0 \% ; 0,15,5 ; p=n . s .) \\
\text { H1N2 } \\
\text { Personnes exposées }-7 / 118 \\
(5,9 \% ; 2,4 ; 11,9 ; p=0,01) \\
\text { Abatteurs }-3 / 50 \\
(6 \% ; 1,2 ; 16,6 ; p=0,025) \\
\text { Agriculteurs }-2 / 46 \\
(4,3 \% ; 0,5 ; 14,9 ; p=0,077) \\
\text { Vétérinaires }-2 / 22 \\
(9,1 \% ; 1,1 ; 29,2 ; p=0,024) \\
\text { H3N2 } \\
\text { Personnes exposées }-16 / 118 \\
(13,6 \% ; 7,9 ; 21,1 ; p<0,001) \\
\text { Abatteurs }-7 / 50 \\
(14 \% ; 5,8 ; 26,8 ; p<0,001) \\
\text { Agriculteurs }-4 / 46 \\
(8,7 \% ; 2,4 ; 20,8 ; p=0,006) \\
\text { Vétérinaires - } 5 / 22 \\
(22,7 \% ; 7,8 ; 45,4 ; p<0,001) \\
\text { le virus de la grippe porcine observée } \\
\text { dans un petit nombre de cas }\end{array}$ & $\|-2$ & Bon \\
\hline
\end{tabular}




\begin{tabular}{|c|c|c|c|c|c|c|}
\hline \multicolumn{7}{|c|}{ PERSONNES AVEC UNE EXPOSITION PROFESSIONNELLE AUX POPULATIONS PORCINES } \\
\hline Étude & $\begin{array}{l}\text { Modèle } \\
\text { d'étude }\end{array}$ & Participants & Type de grippe & Principales conclusions & Niveau & Qualité \\
\hline $\begin{array}{l}\text { Lopez-Robles G. } \\
(2012)^{66}\end{array}$ & $\begin{array}{l}\text { Dépistage } \\
\text { sérologique, } \\
\text { transversal }\end{array}$ & $\begin{array}{l}\mathrm{N}=125 \\
\mathrm{n}_{\text {exposé }}=62 \\
\mathrm{n}_{\text {témoin }}=63 \\
\text { Ouvriers de } 15 \\
\text { fermes porcines } \\
\text { commerciales; } \\
\text { témoins d'activités } \\
\text { non liées à } \\
\text { l'industrie } \\
\text { Mexique, } \\
\text { 2007-2008 }\end{array}$ & $\begin{array}{l}\text { Humaine } \\
\text { A/New } \\
\text { Caledonia/20/99 } \\
\text { (H1N1) } \\
\text { Virus analogue } \\
\text { à A/Panama/ } \\
\text { 2001/99 (H3N2) } \\
\text { Porcine } \\
\text { A/Swine/ } \\
\text { England/ } \\
\text { 163266/87 } \\
\text { (segments de lignée } \\
\text { humaine H3N2) } \\
\text { A/Swine/ } \\
\text { Wisconsin/ } \\
\text { 238/97 (H1N1) }\end{array}$ & $\begin{array}{l}\text { RT-PCR, Test IH (séropositif avec } \\
\text { titres } \geq 1: 32 \text { ) } \\
\text { Signes sérologiques d'une } \\
\text { exposition antérieure à la grippe } \\
\text { porcine et à la grippe humaine } \\
\text { détectés } \\
\text { Les personnes exposées présentai- } \\
\text { ent une séroprévalence du SIV plus } \\
\text { grande, mais une séroprévalence de } \\
\text { la grippe humaine plus faible que le } \\
\text { groupe témoin } \\
1 \text { des } 62 \text { personnes exposées était } \\
\text { atteinte des virus de la grippe } \\
\text { porcine et humaine } \mathrm{H} 1 \mathrm{~N} 1 ; 5 \text { étaient } \\
\text { atteintes des virus de la grippe } \\
\text { porcine et humaine } \mathrm{H} 3 \mathrm{~N} 2 \\
1 \text { témoin avait des anticorps contre } \\
\text { le virus de la grippe porcine H3N2 } \\
\text { Antécédents de vaccination } \\
\text { contre la grippe conférant } \\
\text { une protection contre le virus } \\
\text { de la grippe porcine } \mathrm{H} 3 \mathrm{~N} 2 \\
\text { (TRA = 0,05; } 0,01 ; 0,52 ; \mathrm{P}<0,05 \text { ) }\end{array}$ & III & $\begin{array}{l}\text { Passable } \\
\text { Les personnes } \\
\text { non exposées } \\
\text { n'ont pas été } \\
\text { choisies de façon } \\
\text { aléatoire; elles ont } \\
\text { fait l'objet d'un } \\
\text { biais de sélection } \\
\text { et peuvent ne pas } \\
\text { représenter la } \\
\text { population } \\
\text { générale }\end{array}$ \\
\hline
\end{tabular}




\begin{tabular}{|c|c|c|c|c|c|c|}
\hline \multicolumn{7}{|c|}{ PERSONNES AVEC UNE EXPOSITION PROFESSIONNELLE AUX POPULATIONS PORCINES } \\
\hline Étude & $\begin{array}{l}\text { Modèle } \\
\text { d'étude }\end{array}$ & Participants & Type de grippe & Principales conclusions & Niveau & Qualité \\
\hline Myers K.P. $(2006)^{67}$ & $\begin{array}{l}\text { Séroprévalence } \\
\text { transversale }\end{array}$ & $\begin{array}{l}\mathrm{N}=352 \\
\mathrm{n}_{\text {agriculteur }}=111 \\
\mathrm{n}_{\text {usine de transformation }}=97 \\
\mathrm{n}_{\text {vétérinaire }}=65 \\
\mathrm{n}_{\text {témoin }}=79 \\
\text { Personnes } \\
\text { exposées aux } \\
\text { porcs (agriculteurs, } \\
\text { ouvriers d'usines } \\
\text { de transformation } \\
\text { de la viande, } \\
\text { vétérinaires, } \\
\text { techniciens } \\
\text { vétérinaires); } \\
\text { groupe témoin } \\
\text { composé de } \\
\text { volontaires de } \\
\text { l'université non } \\
\text { exposés aux porcs } \\
\text { dans le cadre de } \\
\text { leur travail } \\
\text { É.-U., 2002-2004 }\end{array}$ & $\begin{array}{l}\text { Humaine } \\
\text { A/New Caledonia/ } \\
\text { 20/99 (H1N1) } \\
\text { A/Panama/ } \\
\text { 2007/99 (H3N2) } \\
\text { A/Nanchang/ } \\
\text { 933/95 (H3N2) } \\
\text { Porcine } \\
\text { A/Swine/Wl/ } \\
\text { 238/97 (H1N1) } \\
\text { A/Swine/Wl/ } \\
\text { R33F/01 (H1N2) } \\
\text { A/Swine/ } \\
\text { Minnesota/ } \\
\text { 593/99 (H3N2) }\end{array}$ & 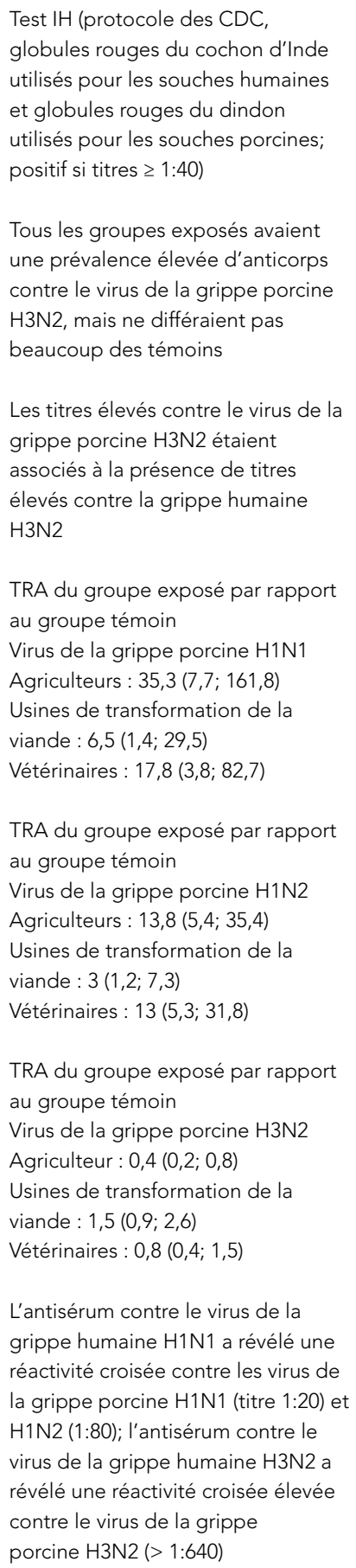 & III & $\begin{array}{l}\text { Passable } \\
\text { Le groupe témoin } \\
\text { est composé de } \\
\text { volontaires et } \\
\text { peut ne pas } \\
\text { représenter la } \\
\text { population } \\
\text { générale. II diffère } \\
\text { du groupe exposé } \\
\text { relativement à } \\
\text { l'âge et au sexe }\end{array}$ \\
\hline
\end{tabular}




\begin{tabular}{|c|c|c|c|c|c|c|}
\hline \multicolumn{7}{|c|}{ PERSONNES AVEC UNE EXPOSITION PROFESSIONNELLE AUX POPULATIONS PORCINES } \\
\hline Étude & $\begin{array}{l}\text { Modèle } \\
\text { d'étude }\end{array}$ & Participants & Type de grippe & Principales conclusions & Niveau & Qualité \\
\hline Olsen C.W. (2002) $)^{68}$ & $\begin{array}{l}\text { Enquête avec } \\
\text { dépistage } \\
\text { sérologique }\end{array}$ & $\begin{array}{l}\mathrm{N}=76 \\
\mathrm{~N}_{\text {échantillon témoin }}=114 \\
\text { Agriculteurs, } \\
\text { ouvriers agricoles, } \\
\text { époux et enfants, } \\
\text { vétérinaires dans } \\
\text { des exploitations } \\
\text { agricoles; } \\
\text { échantillons de } \\
\text { contrôle de sérum } \\
\text { de résidents } \\
\text { urbains } \\
\text { É.-U., sept. } 1996 \text { à } \\
\text { avr. } 1997\end{array}$ & $\begin{array}{l}\text { Humaine } \\
\text { A/Johannesburg/ } \\
\text { 82/96 (H1N1) } \\
\text { A/Nanchang/ } \\
\text { 933/95 (H3N2) } \\
\text { Porcine } \\
\text { A/Swine/Indiana/ } \\
\text { 1726/88 (H1N1) } \\
\text { A/Nebraska/ } \\
\text { 01/92 (isolats humains } \\
\text { zoonotiques de virus } \\
\text { de la grippe porcine } \\
\text { H1N1) }\end{array}$ & $\begin{array}{l}\text { Test IH (globules rouges du poulet; } \\
\text { augmentation par facteur de quatre } \\
\text { du titre, titres } \geq 40 \text { et } \geq 80 \text { analysés } \\
\text { plus en détail) } \\
\text { Aucune réactivité croisée détectée } \\
\text { entre les souches humaines et } \\
\text { porcines } \\
\text { Les échantillons de sérum } \\
\text { d'avant-saison provenant de } 17 \text { des } \\
74 \text { participants agricoles étaient } \\
\text { séropositifs à l'un ou l'autre des } \\
\text { deux virus de la grippe porcine (15 } \\
\text { sur } 17 \text { étaient séropositifs aux deux) } \\
\text { comparativement à } 1 \text { des } 114 \\
\text { témoins, p < } 0,001 \\
\text { Les MGT contre les virus humains ne } \\
\text { différaient pas beaucoup de celles } \\
\text { du groupe témoin } \\
3 \text { des } 74 \text { participants agricoles ont } \\
\text { connu des augmentations de titres } \\
\text { par facteur de quatre contre l'un ou } \\
\text { l'autre des virus de la grippe porcine } \\
\text { Facteurs associés à la séropositivité } \\
\text { pour le virus de la grippe porcine : } \\
\text { être agriculteur; faire partie d'une } \\
\text { famille d'agriculteur; avoir } 50 \text { ans ou } \\
\text { plus }\end{array}$ & III & $\begin{array}{l}\text { Passable } \\
\text { Exposition des } \\
\text { témoins urbains } \\
\text { non connue, car } \\
\text { ils ont été } \\
\text { obtenus à partir } \\
\text { d'une sérothèque }\end{array}$ \\
\hline Olsen C.W. $(2006)^{69}$ & Déclaration de cas & $\begin{array}{l}\mathrm{n}=1 \\
\text { Ouvrier agricole } \\
\text { Canada, } 2005\end{array}$ & $\begin{array}{l}\text { Virus réassorti triple } \\
\text { A/Ontario/RV1273/05 }\end{array}$ & $\begin{array}{l}\text { Virus détecté au cours du bilan } \\
\text { diagnostique d'un ouvrier, mais il } \\
\text { n'est pas clair si l'ouvrier a été } \\
\text { activement infecté } \\
\text { Plusieurs autres virus de la grippe de } \\
\text { type A ont été isolés de porcs au } \\
\text { Canada (Man., Alb., C.-B., Ont.) et } \\
\text { de dindons } \\
\text { Il a été révélé que les virus d'origine } \\
\text { animale (porcs et dindons) et } \\
\text { humaine sont issus d'une seule } \\
\text { lignée; ils partagent aussi un } \\
\text { génotype réassorti triple humain/ } \\
\text { porcin classique/aviaire, le virus de } \\
\text { la grippe H3N2 ayant été détecté } \\
\text { chez le porc aux États-Unis en } 1998\end{array}$ & III & Bon \\
\hline
\end{tabular}




\begin{tabular}{|c|c|c|c|c|c|c|}
\hline \multicolumn{7}{|c|}{ PERSONNES AVEC UNE EXPOSITION PROFESSIONNELLE AUX POPULATIONS PORCINES } \\
\hline Étude & $\begin{array}{l}\text { Modèle } \\
\text { d'étude }\end{array}$ & Participants & Type de grippe & Principales conclusions & Niveau & Qualité \\
\hline Ramirez A. $(2006)^{70}$ & $\begin{array}{l}\text { Enquête } \\
\text { transversale avec } \\
\text { dépistage } \\
\text { sérologique }\end{array}$ & $\begin{array}{l}\mathrm{N}=128 \\
\mathrm{n}_{\text {exposé }}=49 \\
\mathrm{n}_{\text {témoin }}=79 \\
\text { Personnes ayant } \\
\text { travaillé dans une } \\
\text { porcherie au cours } \\
\text { des } 12 \text { derniers } \\
\text { mois; Témoins } \\
\text { sélectionnés dans } \\
\text { une étude } \\
\text { concomitante à } \\
\text { l'université } \\
\text { La majorité des } \\
\text { personnes } \\
\text { exposées étaient } \\
\text { des hommes, alors } \\
\text { que la majorité } \\
\text { des témoins } \\
\text { étaient des } \\
\text { femmes } \\
\text { États-Unis, } \\
2004-2005\end{array}$ & S.O. & $\begin{array}{l}\text { Test IH (globules rouges du cochon } \\
\text { d'Inde utilisés pour les souches } \\
\text { humaines, globules rouges du } \\
\text { dindon utilisés pour les souches } \\
\text { porcines; résultats regroupés dans } \\
\text { les titres < } 10 \text { et }>10 \text { ) } \\
\text { Les ouvriers qui ne portent jamais de } \\
\text { gants ou qui en portent rarement } \\
\text { sont plus susceptibles d'avoir des } \\
\text { titres élevés (IH > 10) comparative- } \\
\text { ment aux témoins (TRA : } 30,3 ; 3,8 ; \\
243,5 \text { ) et à d'autres ouvriers ayant } \\
\text { toujours porté des gants ou en ayant } \\
\text { porté la plupart du temps (TRA: } \\
12,7 ; 1,1 ; 151,1 \text { ) }\end{array}$ & III & Passable \\
\hline $\begin{array}{l}\text { Robinson J.L. } \\
(2007)^{71}\end{array}$ & $\begin{array}{l}\text { Enquête avec } \\
\text { dépistage } \\
\text { sérologique }\end{array}$ & $\begin{array}{l}\mathrm{N}=54 \\
\text { Membres d'une } \\
\text { exploitation } \\
\text { agricole } \\
\text { communautaire où } \\
\text { un enfant en bas } \\
\text { âge avait été } \\
\text { hospitalisé en } \\
\text { raison d'un virus } \\
\text { de la grippe } \\
\text { porcine } \\
\text { Canada, } 2006\end{array}$ & $\begin{array}{l}\text { Humaine } \\
\text { A/New } \\
\text { Caledonia/ } \\
\text { 20/99 (H1N1) } \\
\text { A/Wisconsin/ } \\
67 / 2005 \text { (H3N2) } \\
\text { Porcine } \\
\text { A/Ontario/ } \\
\text { RV1273/2005 } \\
\text { (virus de la grippe } \\
\text { porcine H3N2) } \\
\text { A/Canada/ } \\
\text { 1158/2006 (détecté } \\
\text { chez un enfant en bas } \\
\text { âge) }\end{array}$ & $\begin{array}{l}\text { Test IH (globules rouges du cochon } \\
\text { d'Inde; positif au titre } \geq 32 \text { ), RT-PCR } \\
8 \text { autres membres de } 3 \text { ménages } \\
\text { étaient séropositifs (IH } \geq 32 \text { ) (4 } \\
\text { provenaient du ménage du patient } \\
\text { de référence) } \\
\text { La plupart d'entre eux n'avaient pas } \\
\text { été exposés à des porcs ou l'avaient } \\
\text { été moins d'une heure par semaine } \\
\text { L'écouvillonnage nasal chez } 25 \text { porcs } \\
\text { en croissance a révélé un résultat } \\
\text { négatif pour le virus de la grippe } \\
\text { porcine (SIV) } \\
\text { Quatre des dix échantillons de } \\
\text { sérum porcin étaient positifs pour le } \\
\text { virus de la grippe H3N2, un } \\
\text { échantillon étant séropositif pour le } \\
\text { A/Canada/1158/2006 }\end{array}$ & III & Bon \\
\hline
\end{tabular}




\begin{tabular}{|c|c|c|c|c|c|c|}
\hline \multicolumn{7}{|c|}{ PERSONNES AVEC UNE EXPOSITION PROFESSIONNELLE AUX POPULATIONS PORCINES } \\
\hline Étude & $\begin{array}{l}\text { Modèle } \\
\text { d'étude }\end{array}$ & Participants & Type de grippe & Principales conclusions & Niveau & Qualité \\
\hline Terebuh P. $(2010)^{72}$ & $\begin{array}{l}\text { Cohortes } \\
\text { prospectives } \\
\text { (surveillance des } \\
\text { humains et des } \\
\text { porcs avec } \\
\text { dépistage } \\
\text { sérologique) }\end{array}$ & $\begin{array}{l}\mathrm{n}_{\text {ouvrier a1 }}=88 \text { (85\% } \\
\text { du recrutement } \\
\text { initial) } \\
\mathrm{n}_{\text {ouvrier a2 }}=76 \text { (78\% } \\
\text { du recrutement } \\
\text { initial) } \\
2 \text { témoins appariés } \\
\text { selon l'âge (en } \\
5 \text { ans) par ouvrier; } \\
210 \text { échantillons } \\
\text { témoins au cours } \\
\text { de l'a1, } 202 \\
\text { échantillons au } \\
\text { cours de l'a2 } \\
\text { Ouvriers d'une } \\
\text { exploitation de } \\
\text { production } \\
\text { porcine; témoins } \\
\text { provenant de deux } \\
\text { centres urbains } \\
\text { É.- } U ., \text { sept. à mai } \\
2002-2004\end{array}$ & $\begin{array}{l}9 \text { souches grippales } \\
\text { (humaines, porcines et } \\
\text { réassortiment triple) }\end{array}$ & $\begin{array}{l}\text { Test IH (positif au titre } \geq 1: 40 \text { ); sérum } \\
\text { jumelé prélevé au début et à la fin } \\
\text { de l'étude, échantillon de sérum } \\
\text { supplémentaire prélevé auprès } \\
\text { d'ouvriers vaccinés } 2 \text { semaines après } \\
\text { la vaccination } \\
\text { La majorité des ouvriers ont travaillé } \\
\text { avec des porcs pendant au moins } \\
5 \text { ans } \\
\text { Année } 1 \\
15 \text { des } 42 \text { réponses positives auprès } \\
\text { d'ouvriers répondaient à la définition } \\
\text { du syndrome grippal, mais aucun } \\
\text { ouvrier n'était positif quant à la } \\
\text { grippe par culture } \\
111 \text { porcs ont été signalés comme } \\
\text { présentant des signes de syndrome } \\
\text { grippal } \\
52 \text { (59 \%) étaient séropositifs à au } \\
\text { moins un virus humain et } 46 \text { ( } 52 \% \text { ) } \\
\text { étaient séropositifs à au moins un } \\
\text { virus porcin } \\
10 \text { ouvriers ont subi une séroconver- } \\
\text { sion à un ou plusieurs SIV; } 8 \text { ont subi } \\
\text { une séroconversion entre } \\
\text { l'échantillon avant la vaccination et } \\
\text { celui après la vaccination, les deux } \\
\text { autres n'ont pas reçu de vaccin } \\
\text { (augmentation du titre de } 5 \text { à } 20 \text { ) } \\
\text { La séropositivité au SIV est associée } \\
\text { cours de l'année } 1 \text { seulement }\end{array}$ & $\|-2$ & $\begin{array}{l}\text { Bon } \\
\text { Les périodes } \\
\text { d'étude ont } \\
\text { correspondu à la } \\
\text { saison du virus de } \\
\text { la grippe } \\
\text { humaine, aucune } \\
\text { surveillance } \\
\text { n'ayant eu lieu } \\
\text { pendant l'été, } \\
\text { bien que des } \\
\text { éclosions porcines } \\
\text { aient quand } \\
\text { même eu lieu }\end{array}$ \\
\hline
\end{tabular}


PERSONNES AVEC UNE EXPOSITION PROFESSIONNELLE AUX POPULATIONS PORCINES

\begin{tabular}{|c|c|c|c|c|c|c|}
\hline Étude & $\begin{array}{l}\text { Modèle } \\
\text { d'étude }\end{array}$ & Participants & Type de grippe & Principales conclusions & Niveau & Qualité \\
\hline & & & & $\begin{array}{l}\text { Année } 2 \\
11 \text { des } 32 \text { réponses positives auprès } \\
\text { d'ouvriers concordaient avec la } \\
\text { définition du syndrome grippal; } \\
1 \text { était positive pour la grippe } \\
111 \text { porcs ont été signalés comme } \\
\text { présentant des signes de syndrome } \\
\text { grippal } \\
55 \text { (72 \%) étaient séropositifs à au } \\
\text { moins un virus humain et } 47 \text { (62\%) } \\
\text { étaient séropositifs à au moins un } \\
\text { virus porcin } \\
29 \text { ouvriers ont subi une séroconver- } \\
\text { sion à un ou plusieurs SIV } \\
\text { Des blessures liées aux aiguilles } \\
\text { utilisées pour le vaccin contre la } \\
\text { grippe porcine ont touché } 4 \text { (4 \%) et } \\
11 \text { (14 \%) ouvriers au cours de } \\
\text { l'année } 1 \text { et de l'année } 2 \text {, } \\
\text { respectivement } \\
\text { Les TRA des ouvriers pour trois SIV } \\
\text { étaient significativement plus élevés } \\
\text { que ceux des témoins ( } \mathrm{p}<0,0001 \text { ) } \\
17 \text { étaient positifs pour la grippe A } \\
\text { par RT-PCR }\end{array}$ & & \\
\hline
\end{tabular}




\section{NIVEAUX DE PREUVE FONDÉS SUR LA MÉTHODOLOGIE DE LA RECHERCHE}

\begin{tabular}{l|l}
\hline I & Données probantes obtenues dans le cadre d'essais comparatifs randomisés. \\
\hline II-1 & Données probantes obtenues dans le cadre d'essais comparatifs, sans randomisation. \\
\hline II-2 & $\begin{array}{l}\text { Données probantes obtenues dans le cadre d'études analytiques de cohortes ou cas/témoins, réalisées de préférence dans plus d'un centre ou par } \\
\text { plus d'un groupe de recherche au moyen d'indicateurs cliniques de résultats de l'efficacité d'un vaccin. }\end{array}$ \\
\hline II-3 & $\begin{array}{l}\text { Données probantes provenant d'études de plusieurs séries chronologiques avec ou sans intervention. Les résultats spectaculaires obtenus dans un } \\
\text { contexte non contrôlé (comme les résultats de l'introduction de la pénicilline dans les années 1940) pourraient aussi être considérés comme faisant } \\
\text { partie de ce type de données probantes. }\end{array}$ \\
\hline III & Opinions d'experts respectés reposant sur l'expérience clinique, des études descriptives et des études de cas ou des rapports de comités d'experts. \\
\hline
\end{tabular}

\section{COTE DE QUALITÉ DES PREUVES (VALIDITÉ INTERNE)}

\begin{tabular}{l|l}
\hline Bon & Étude (notamment les méta-analyses ou les recensions systématiques) répondant bien à tous les critères propres à la méthodologie*. \\
\hline Passable & $\begin{array}{l}\text { Étude (notamment les méta-analyses ou les recensions systématiques) ne répondant pas (ou du moins pas clairement) à au moins un critère } \\
\text { propre à la méthodologie*, mais n'ayant pas de « lacune majeure » connue. }\end{array}$ \\
\hline Médiocre & $\begin{array}{l}\text { Étude (notamment les méta-analyses ou les recensions systématiques) ayant au moins une « lacune majeure » propre à la méthodologie* ou une } \\
\text { accumulation de lacunes moins importantes ne permettant pas de formuler des recommandations à partir des résultats de l'étude. }\end{array}$
\end{tabular}

* Les critères généraux propres à la méthodologie sont décrits dans l'article de Harris et coll., 200173 


\section{Annexe B : Recommandations nationales concernant la vaccination antigrippale saisonnière pour les ouvriers exposés aux animaux dans le cadre de leur travail}

\begin{tabular}{|c|c|c|c|}
\hline Pays & Organisation & Recommandations & Référence \\
\hline \multirow[t]{2}{*}{ Canada } & $\begin{array}{l}\text { Agence de la santé } \\
\text { publique du Canada - } \\
\text { Comité consultatif national } \\
\text { de l'immunisation } \\
\text { (ASPC - CCNI) }\end{array}$ & $\begin{array}{l}\text { Personnes en contact direct avec de la volaille infectée par le virus } \\
\text { de la grippe aviaire durant les activités d'abattage. } \\
\text { On peut définir le contact direct comme une exposition suffisante à } \\
\text { la volaille infectée pour favoriser la transmission du virus de la } \\
\text { grippe aviaire à la personne exposée. Les sujets visés sont ceux qui } \\
\text { font l'abattage, ainsi que tous ceux qui sont directement exposés } \\
\text { au virus de la grippe aviaire, tels que les vétérinaires chargés de la } \\
\text { supervision et les inspecteurs. }\end{array}$ & $\begin{array}{l}\text { Une déclaration d'un comité } \\
\text { consultatif (DCC). } \\
\text { Comité consultatif national de } \\
\text { l'immunisation (CCNI). Déclaration } \\
\text { sur la vaccination antigrippale pour } \\
\text { la saison 2011-2012 }\end{array}$ \\
\hline & $\begin{array}{l}\text { Agence canadienne } \\
d^{\prime} \text { inspection des aliments } \\
\text { (ACIA) }\end{array}$ & $\begin{array}{l}\text { Vaccination des personnes travaillant dans le système de } \\
\text { production alimentaire comme mesure de biosécurité. } \\
\text { (L'ACIA utilise la déclaration du CCNI selon laquelle tous les } \\
\text { Canadiens en santé reçoivent le vaccin antigrippal saisonnier } \\
\text { dans le but d'encourager les producteurs et leur famille, les } \\
\text { ouvriers agricoles, les vétérinaires, le personnel du service } \\
\text { agricole — notamment les conducteurs de véhicules transportant } \\
\text { des aliments pour animaux, les équipes de vaccination et } \\
\text { d'insémination — et les autres personnes visitant les porcheries } \\
\text { à recevoir le vaccin saisonnier.) }\end{array}$ & $\begin{array}{l}\text { Site Web de I'ACIA sur la biosécurité } \\
\text { animale } \\
\text { www.inspection.gc.ca/animaux/ } \\
\text { animaux-terrestres/biosecurite/ } \\
\text { fra/1299868055616/1320534707863 }\end{array}$ \\
\hline Australie & $\begin{array}{l}\text { National Health and } \\
\text { Medical Research } \\
\text { Council, Department } \\
\text { of Health and Ageing }\end{array}$ & $\begin{array}{l}\text { Personnes travaillant dans l'industrie avicole commerciale } \\
\text { ou dans l'abattage de volailles pendant une activité de grippe } \\
\text { aviaire confirmée. } \\
\text { Une vaccination basée sur la composition actuelle du vaccin } \\
\text { antigrippal saisonnier est recommandée pour les ouvriers avicoles } \\
\text { et les autres personnes en contact étroit direct avec les volailles } \\
\text { pendant une éclosion de grippe aviaire. Bien que le vaccin } \\
\text { antigrippal systématique ne protège pas contre la grippe aviaire, } \\
\text { il est possible qu'une personne infectée en même temps par les } \\
\text { souches aviaires et humaines du virus grippal provoque un } \\
\text { réassortiment des deux souches pour former une souche virulente } \\
\text { pouvant se propager d'une personne à une autre (c.-à-d. créer } \\
\text { une pandémie). }\end{array}$ & $\begin{array}{l}\text { Guide d'immunisation australien, } \\
9 \text { e édition. (Dernière mise à jour le } \\
26 \text { mars 2008) } \\
\text { www.immunise.health.gov.au/internet/ } \\
\text { immunise/publishing.nsf/Content/ } \\
\text { Handbook-influenza } \\
\text { (Cette recommandation n'est pas } \\
\text { énoncée dans la déclaration annuelle } \\
\text { sur la grippe saisonnière de } 2012 \\
\text { produite par l'Australian Technical } \\
\text { Advisory Group on Immunisation } \\
\text { [ATAGI], bien qu'elle ait été rédigée par } \\
\text { les auteurs du guide d'immunisation.) }\end{array}$ \\
\hline Hong Kong & $\begin{array}{l}\text { Centre for Health } \\
\text { Protection, Department } \\
\text { of Health-Scientific } \\
\text { Committee on Vaccine } \\
\text { Preventable Diseases }\end{array}$ & $\begin{array}{l}\text { Ouvriers des poulaillers : La vaccination antigrippale saisonnière est } \\
\text { recommandée pour les ouvriers des poulaillers et les personnes } \\
\text { abattant des poulets potentiellement infectés par le virus de la } \\
\text { grippe aviaire hautement pathogène afin de réduire le plus } \\
\text { possible le risque de réassortiment et d'une émergence éventuelle } \\
\text { d'un nouveau virus grippal ayant un potentiel pandémique au } \\
\text { moyen de la prévention des infections concomitantes par les virus } \\
\text { de la grippe humaine et de la grippe aviaire chez les humains. } \\
\text { Éleveurs de porcs et personnes dans l'industrie de l'abattage des } \\
\text { porcs: On recommande aux éleveurs de porcs et personnes dans } \\
\text { l'industrie de l'abattage des porcs de se faire vacciner contre la } \\
\text { grippe saisonnière afin de prévenir l'émergence d'un nouveau virus } \\
\text { de la grippe A chez les humains ou les hôtes tels que les porcs. }\end{array}$ & $\begin{array}{l}\text { Recommandations sur la vaccination } \\
\text { antigrippale pour la saison 2011-2012 } \\
\text { www.chp.gov.hk/files/pdf/recommenda- } \\
\text { tions_on_seasonal_influenza_vaccina- } \\
\text { tion_for_the_201112_season.pdf }\end{array}$ \\
\hline
\end{tabular}




\begin{tabular}{|c|c|c|c|}
\hline Royaume-Uni & $\begin{array}{l}\text { Joint Council on } \\
\text { Vaccination and } \\
\text { Immunisation (JCVI) }\end{array}$ & $\begin{array}{l}\text { Un programme de vaccination antigrippale annuelle pour les } \\
\text { ouvriers avicoles a été lancé pendant la saison 2006-2007 à la suite } \\
\text { d'une recommandation du comité consultatif sur les pathogènes } \\
\text { dangereux (ACDP). Ce programme a fait l'objet d'un examen en } \\
2010 \text { dans le cadre duquel le comité mixte a signalé que la mise en } \\
\text { place du programme était difficile et que le taux de vaccination de } \\
\text { cette population était faible. Étant donné que la grippe aviaire } \\
\text { survient peu fréquemment au Royaume-Uni et en Europe, le risque } \\
\text { d'activité de réassortiment est très faible. Le comité mixte sur la } \\
\text { vaccination et l'immunisation a informé qu'il n'y avait aucun avantage } \\
\text { associé au maintien de la vaccination antigrippale systématique pour } \\
\text { les ouvriers avicoles au-delà de la saison 2010-2011. } \\
\text { En } 2006 \text { et en 2009, l'ACDP a informé le comité mixte sur la } \\
\text { vaccination et l'immunisation qu'il n'était pas nécessaire d'offrir le } \\
\text { vaccin antigrippal saisonnier aux personnes travaillant dans } \\
\text { l'industrie porcine comme mesure de santé publique à titre de } \\
\text { précaution en raison des données probantes limitées quant au } \\
\text { rôle des porcs dans la transmission de la grippe aux humains. Le } \\
\text { comité consultatif juge aussi que le risque de réassortiment des } \\
\text { virus de la grippe porcine et humaine est faible. }\end{array}$ & $\begin{array}{l}\text { Comité mixte sur la vaccination et } \\
\text { l'immunisation : Comptes-rendus } \\
\text { provisoires } \\
\text { 6 octobre } 2010 \\
\text { www.dh.gov.uk/prod_consum_dh/ } \\
\text { groups/dh_digitalassets/@dh/@ab/ } \\
\text { documents/digitalasset/dh_124596.pdf } \\
17 \text { juin 2009 } \\
\text { www.dh.gov.uk/prod_consum_dh/ } \\
\text { groups/dh_digitalassets/@dh/@ab/ } \\
\text { documents/digitalasset/dh_116040.pdf }\end{array}$ \\
\hline \multirow[t]{2}{*}{ États-Unis } & \multirow{2}{*}{$\begin{array}{l}\text { Centers for Disease } \\
\text { Control and Prevention } \\
\text { Advisory Committee on } \\
\text { Immunization Practices } \\
\text { (CDC-ACIP) }\end{array}$} & $\begin{array}{l}\text { Les CDC ont recommandé que les personnes responsables } \\
d^{\prime} \text { intervenir en cas d'éclosions de la grippe aviaire chez la volaille } \\
\text { reçoivent un vaccin antigrippal saisonnier. }\end{array}$ & $\begin{array}{l}\text { Prévention et contrôle de la grippe par } \\
\text { la vaccination. Recommandations de } \\
\text { I'ACIP, } 2010 .\end{array}$ \\
\hline & & $\begin{array}{l}\text { [...] vaccination antigrippale des ouvriers de porcheries — peu } \\
\text { importe s'il présente un risque élevé ou non - est importante pour } \\
\text { réduire le risque de transmission du virus de la grippe saisonnière } \\
\text { des personnes malades aux porcs. La vaccination antigrippale } \\
\text { saisonnière des ouvriers peut aussi diminuer le potentiel d'une } \\
\text { co-infection des personnes ou des porcs par les virus de la grippe } \\
\text { humaine et de la grippe porcine. De telles infections doubles } \\
\text { pourraient créer un réassortiment génétique des deux virus différents } \\
\text { de la grippe A et aboutir à un nouveau virus de la grippe A ayant une } \\
\text { combinaison différente de gènes et qui soulèverait une préoccupa- } \\
\text { tion majeure en matière de santé publique. }\end{array}$ & $\begin{array}{l}\text { Directives provisoires des CDC à } \\
\text { l'intention des ouvriers travaillant dans } \\
\text { les fermes porcines commerciales : } \\
\text { prévenir la propagation des virus } \\
\text { grippaux A } \\
\text { www.cdc.gov/flu/swineflu/guidance- } \\
\text { commercial-pigs.htm }\end{array}$ \\
\hline Allemagne & $\begin{array}{l}\text { German Committee for } \\
\text { Biological Agents }\end{array}$ & $\begin{array}{l}\text { [...] Depuis } 2003 \text {, le comité allemand contre les agents biologiques a } \\
\text { recommandé la vaccination antigrippale saisonnière des personnes } \\
\text { exposées à des oiseaux ou volailles infectés par le virus A/H5N1. }\end{array}$ & 11 \\
\hline
\end{tabular}

